\title{
WELFARE IMPACTS OF INDEX INSURANCE IN THE Presence of A PoVerty Trap
}

\author{
Sommarat Chantarat, Andrew G. Mude, Christopher B. Barrett and Calum G. Turvey*
}

June 2014 revised version

\begin{abstract}
This paper evaluates the effectiveness of an index-based livestock insurance (IBLI) product designed to compensate for area average predicted livestock mortality loss in northern Kenya, where previous work has established the presence of poverty traps. We simulate household-specific wealth dynamics based on a model parameterized using rich panel and experimental data from the region. The simulations allow us to investigate patterns of willingness to pay for asset index insurance that is imperfectly correlated with individuals' loss experience. The bifurcated livestock dynamics associated with the poverty trap gives rise to insurance valuation that is highly nonlinear in individual herd size. Willingness to pay among vulnerable groups who most need insurance are, on average, lower than commercially viable rates. And subsidization of IBLI premiums appears to offer more cost-effective poverty reduction than direct transfers to the poor.
\end{abstract}

Keywords: Index insurance, asset risk, bifurcated wealth dynamics, nonlinear growth, poverty traps, safety net, risk preference elicitation, pastoralists, Kenya

\footnotetext{
* The authors are at Crawford School of Public Policy at the Australian National University, International Livestock Research Institute, Nairobi, Kenya and Charles Dyson School of Applied Economics and Management, Cornell University, respectively. Chantarat is the corresponding author and can be contacted at Sommarat.chantarat@anu.edu.au. This research was funded through a USAID Norman E. Borlaug Leadership Enhancement in Agriculture Program Doctoral Dissertation Improvement Grant, the World Bank Commodity Risk Management Program, the USAID Assets and Market Access Collaborative Research Support Program, the International Livestock Research Institute and the Graduate School of Cornell University. Data were made available by the Pastoral Risk Management project of the Global Livestock Collaborative Research Support Program, funded by the Office of Agriculture and Food Security, Global Bureau, USAID, under grant number DAN-1328-G-00-0046-00. We thank Michael Carter, Munenobu Ikegarmi, John McPeak, Sharon Tennyson and seminar participants at Cornell University, George Washington University, Agricultural and Applied Economics Annual Meeting 2009, the Economics of Index Insurance Workshop at the FAO, Rome, Italy and the International Livestock Research Institute, Nairobi, Kenya, for their helpful comments. The opinions expressed do not necessarily reflect the views of the U.S. Agency for International Development or the World Bank. Any remaining errors are the authors' sole responsibility.
} 


\section{Introduction}

Index insurance has gained widespread interest in recent years as an instrument for reducing uninsured covariate risk in poor rural areas that typically lack access to commercial insurance products. These financial instruments make indemnity payments based on realizations of an underlying index - based on some objectively measured random variable - relative to a pre-specified threshold, the "strike" (Barnett et al. 2008). Index insurance offers significant potential advantages over traditional insurance. Because indemnity payments are not based on individual claims, insurance companies and insured clients need only monitor the index to know when payments are due. This sharply reduces the transaction costs of monitoring and verifying losses, while also eliminating the asymmetric information problems (i.e., adverse selection and moral hazard) that bedevil conventional insurance. These advantages have sparked considerable interest in index insurance for poor regions otherwise lacking formal insurance access (Barnett and Mahul 2007).

The advantages of reduced transaction costs and asymmetric information problems, however, come at the cost of increased "basis risk", the imperfect correlation between an insured's loss experience and the behavior of the underlying index on which the index insurance contract is written (Norton et al 2013; Woodard et al. 2008). A contract holder may experience losses but not receive a payout if the overall index is not triggered. Conversely, the aggregate experience may trigger indemnity payments even to insurees who experience no loss.

Given this tradeoff between basis risk and reduced incentive problems and transactions costs, the impact of index insurance on well-being remains underinvestigated, especially in the case of index insurance on assets that determine the time path of future earnings and welfare. And because the current experience of index insurance has thus far been plagued by limited uptake and predictable questions about the quality of the initial contracts (Binswanger-Mkhize 2012), empirical evidence on the impact of index insurance on the well-being of otherwise-uninsured poor populations remain quite rare. This paper offers some initial, ex ante impact assessment of a specific index insurance contract that launched in Northern Kenya in 2010. It also offers an innovative approach to establishing the ex ante welfare effects of and willingness to pay 
for asset insurance and demonstrates how the presence of asset thresholds associated with poverty traps can affect insurance valuation and effectiveness.

The arid and semi-arid lands (ASAL) of east Africa are among the poorest regions on Earth, with severe (less than $\$ 1 /$ day) poverty rates routinely in excess of $75 \%$. Given meager rainfall and infrastructure, the pastoralist populations who inhabit these areas rely heavily on extensive livestock grazing for their livelihood. Recent economic research, building on extensive prior ethnographic work, finds that east African pastoralists operate in an environment characterized by multiple herd size equilibria characteristic of poverty traps (Lybbert et al. 2004, Barrett et al. 2006, Santos and Barrett 2011). The prominent role that uninsured covariate climate risk plays in driving pastoral poverty traps (Santos and Barrett 2007) and growing concern that droughts are driving growing numbers of pastoralists into destitution (Sandford 2006, Little et al. 2008, Barrett and Santos forthcoming), naturally motivated the recent development of index-based livestock insurance (IBLI) against catastrophic herd loss in the northern Kenyan ASAL (Chantarat et al. 2013). These IBLI products have been commercially piloted since January 2010.

Like typical insurance, IBLI compensates for livestock loss. But unlike traditional insurance, it only compensates for covariate herd losses that are predicted by the historical relationship with remotely sensed Normalized Differential Vegetation Index (NDVI) measures; an indicator of vegetative cover widely used in drought monitoring programs in Africa. These data are publicly available in near-real time and objectively verifiable. Chantarat et al. (2013) explain the details of the IBLI contract design and show that it performs extremely well out-of-sample in insuring against catastrophic covariate shocks in this region. In this paper we use household-level panel data to simulate the impact of IBLI on Northern Kenyan pastoral households' welfare dynamics.

This paper makes several novel contributions to the literature. First, IBLI insures assets rather than income. Although the overwhelming majority of the global insurance market insures assets through property and casualty, life or health insurance products, most index insurance on offer in the developing world focus on replacing lost income, typically due to rainfall shocks that affect crop production. The loss of productive assets like livestock potentially disrupts future income processes, not just current earnings. Furthermore, in the presence of a poverty trap, shocks that push herd sizes below a 
critical threshold at which herd dynamics bifurcate can have especially severe consequences. The point of bifurcation is critical because below this threshold the rate at which the livestock asset is depleted due to death loss far exceeds any short run possibility of rebuilding the herd. Thus insurance that effectively protects households from slipping into the poverty trap can be of especially high value to those near the threshold (Lybbert and Barrett 2011). Conversely, insurance that consumes scarce resources and fails to protect the household from catastrophic shocks can do damage. Given these considerations, we evaluate IBLI's performance using a dynamic simulation model rather than the usual static approach employed in the existing literature. We show that the effectiveness of IBLI depends on initial herd size relative to the bifurcation threshold as well as, to a lesser degree, on household-specific basis risk and risk preferences.

Second, rather than modeling performance for a representative agent, as is the norm in the extant literature (Skees et al. 2001; Turvey and Nayak 2003; Vedenov and Barnett 2004; Deng 2007), we explicitly study how IBLI performance varies based on variation in household characteristics, such as initial herd size, and key basis risk and risk preference parameters. And rather than making assumptions about these parameters, we estimate them from panel data and field experiments from the area. Contracts that perform well for a representative household may not prove effective for target subpopulations. We show that may be the case with IBLI.

Finally, household-level simulation analysis allows us to compare the outcomes of various subsidization programs and targeting schemes. Our analysis finds that IBLI subsidies targeted toward vulnerable-but-non-poor pastoralists create an effective safety net by protecting such households from slipping into a poverty trap after a drought. This reinforces prior work suggesting that safety net interventions targeting the non-poor can reduce poverty in the long run by stemming the rate of inflow into the ranks of the chronically poor following a shock (Barrett et al. 2012).

The rest of the paper is organized as follows. Section 2 briefly explains the study locations and the multiple equilibria poverty trap found in the region. Section 3 introduces IBLI. Section 4 then describes the dynamic model we use in the simulations and introduces the certainty equivalent herd growth rate, which we use as a key 
performance evaluation criterion. Section 5 estimates distributions of basis risk, risk preferences and other key household characteristics necessary for the simulations. Section 6 reports the estimated IBLI performance and how this varies based on identifiable household characteristics. Section 7 estimates households' willingness to pay for the optimal contract and aggregate demand for IBLI. Section 8 then explores how alternative approaches to offering IBLI commercially or with safety net subsidies affect wealth and poverty dynamics in the system. Section 9 concludes.

\section{Pastoralism in northern Kenya and multiple-equilibria poverty traps}

Extensive livestock grazing represents the key livelihood in the northern Kenyan ASAL. Pastoralists move their herds in response to spatiotemporal variability in forage and water access. Northern Kenya experiences bimodal rainfall, defined by long rains that fall March-May, followed by a long dry season (June-September), then a short rains season from October-December followed by a January-February short dry season. We henceforth refer to the March-September period as the LRLD season (for long rains and long dry), and the October-February period as SRSD (for short rains and short dry). When the rains fail, especially over two rainy seasons in a row, catastrophic herd losses commonly ensue.

As seasonal migration is critical to sustain viable herd accumulation but migratory livelihood requires minimum household consumption out of household herd, positive herd growth overtime might not be achievable by everyone in this region. Previous research (Lybbert et al. 2004, McPeak 2004, Barrett et al. 2006, Santos and Barrett 2007, 2011) has indeed found prominent evidence of multiple-equilibria of long-run herd sizes, whereby herd accumulation bifurcates with respect to a critical herd size threshold typically in the range of 10-20 total livestock units (TLU) ${ }^{1}$. Using longitudinal herd accumulation data from the region, this literature found that, on average, herd sizes above the critical threshold tend to grow over time toward a high-level stable equilibrium of 5560 TLU, while herd sizes below this critical herd threshold tend to collapse over time toward irreversible destitution - another stable equilibrium. In the absence of financial markets, pastoral households with small herd sizes are credit constrained and thus unable

\footnotetext{
${ }^{1} 1 \mathrm{TLU}=1$ cattle $=10$ goats or sheep $=0.7$ camels.
} 
to restock toward the critical threshold. They tend to be trapped in a low-level equilibrium poverty trap. The presence of a multiple-equilibria poverty trap in the region also implies that uninsured shocks could have irreversible long-term consequences for herd accumulation and welfare, in particular when shocks make household herds fall below the critical threshold. Insurance that could protect herd size from falling below the threshold could thus be very valuable.

We investigate IBLI performance in Marsabit District, Kenya, for which this product was developed on a pilot basis. We use data from four locations - Dirib Gombo, Logologo, Kargi and North Horr (Figure 1) - from which we have two complementary household-level data sets: panel data collected quarterly from 2000-2002 on around 30 households in each location by the USAID Global Livestock Collaborative Research Support Program "Improving Pastoral Risk Management on East African Rangelands" (PARIMA) project (Barrett et al. 2008), and a separate survey fielded during May-August 2008 among 42 households in each location (Chantarat et al. 2009). The latter survey included field experiments to elicit risk preferences.

\section{[FIGURE 1 ABOUT HERE]}

Table 1 summarizes key characteristics of the four study locations. ${ }^{2}$ Dirib Gombo, on Mount Marsabit, enjoys relatively higher rainfall and is occupied mostly by cattle- and smallstock-keeping Boran pastoralists, who also rely on town-based livelihood opportunities to complement their meager livestock holdings. Logologo is along the main road, with a relatively more arid climate and larger cattle and smallstock herds based on transhumant pastoralism. Kargi and North Horr are very arid locations on opposite edges of the Chalbi dessert, where camel- and smallstock-keeping pastoralists rely on longer distance migrations to cope with greater spatiotemporal variability in forage and water availability.

\section{[TABLE 1 ABOUT HERE]}

Sample households rely on livestock and livestock products for $18-87 \%$ of their income. Severe poverty is widespread and inversely correlated with herd sizes because livestock are the main productive asset owned in the region. As a result, livestock

\footnotetext{
${ }^{2}$ All summary statistics are weighted by appropriate stratified sampling weights.
} 
mortality is considered the main threat to pastoralists' livelihood (Little et al. 2008). Households' seasonal livestock loss 2000-2002 (including a bad drought in 2000) ranged from the lowest average seasonal rate of $7 \%$ in North Horr to a high of $21 \%$ in Dirib Gombo. The long-term consequence of the 2000 catastrophic drought can be seen in the drastic reduction in overall mean herd size from 25 tropical livestock units (TLU) at the beginning of 2000 to 15 TLU at the end of 2008. Extreme ( $>20 \%)$ herd losses occurred in roughly 20\% (10-15\%) of seasons in Dirib Gombo and Logologo (Kargi and North Horr). These catastrophic losses were typically due to covariate shocks related to forage and water availability, while modest losses of individual animals were more commonly idiosyncratic experiences (e.g., due to predators or injury).

\section{Index based livestock insurance}

Chantarat et al. (2013) use a large, repeated cross-sectional household data set collected by the Kenyan government at monthly frequency, 2000-2008, to predict area average herd mortality rates, $\hat{M}$, from satellite-based, remotely sensed vegetation index series, the normalized difference vegetation index for different locations $l$ and seasons $t\left(n d v i_{l t}\right)$ : $\hat{M}_{l t}=\hat{M}\left(n d v i_{l t}\right)$. The resulting predicted livestock mortality rate serves as the index triggering IBLI indemnity payments for that particular location relative to a pre-specified "strike" level, $M^{*}$. The IBLI contract $\left(M^{*}, \hat{M}\left(n d v i_{l t}\right)\right)$ makes indemnity payments $\pi_{l t}\left(M^{*}, \hat{M}\left(n d v i_{l t}\right)\right)$ equal to the difference between predicted losses $\hat{M}\left(n d v i_{l t}\right)$ and the strike $M^{*}$, expressed as a percentage of the insured herd value,

$$
\pi_{l t}\left(M^{*}, \hat{M}\left(n d v i_{l t}\right)\right)=\operatorname{Max}\left(\hat{M}\left(n d v i_{l t}\right)-M^{*}, 0\right) .
$$

For IBLI to be commercially viable, the insurance underwriter adds a premium loading $a \geq 0$ over the actuarially fair rate - i.e., the rate estimated based on the empirical distribution of NDVI - to take into account administrative costs, model uncertainty and 
required profit margins. ${ }^{3}$ The loaded premium rate for coverage season $t$ and location $l$, quoted as a percentage of total insured herd value, can therefore be calculated as

$$
\rho_{l t}^{a}\left(M^{*}, \hat{M}\left(n d v i_{l t}\right)\right)=(1+a) E \pi_{l t}=(1+a) \int \operatorname{Max}\left(\hat{M}\left(n d v i_{l t}\right)-M^{*}, 0\right) d f\left(n d v i_{l t}\right) .
$$

The left panel of Table 2 summarizes the predicted mortality index $\hat{M}\left(n d v i_{l t}\right)$ for each of the four study locations constructed using the full NDVI series available from 1982-2008 and the livestock mortality predictive model developed by Chantarat et al. (2013). The predicted herd mortality indices average 8-9\%. The right panel of Table 2 also shows the actuarially fair IBLI premium rate, which varies across locations due to differences in the distributions of predicted herd mortality index. In what follows, we use 54 seasons of predicted area average herd mortality and the associated fair premium rates to evaluate IBLI performance.

\section{[TABLE 2 ABOUT HERE]}

\section{Analytical framework}

With this simple background on the region, the data and IBLI behind us, we now develop a simple dynamic model that accommodates the nonlinear, bifurcated herd dynamics that describe multiple-equilibria poverty trap previously observed in the region.

\subsection{A stylized model of multiple-equilibria poverty trap}

Denote the herd size, in TLU, realized by household $i$ in location $l$ at the beginning of season $t$ (equivalently, at the end of season $t-1$, where seasons alternate within a year between LRLD and SRSD) as $H_{i l t}$. Herd dynamics are governed by various stochastic processes: the rate of biological reproduction, denoted by $\tilde{b}_{i l t}$, the gross non-biological herd recruitment rate, $\widetilde{i}_{\text {ilt }}$ (which includes purchases, borrowed animals, transfers in, etc.),

\footnotetext{
${ }^{3}$ The average premium loading for agricultural insurance contracts is in the range of $30-50 \%$. See, for example, the USDA Risk Management Agency's or the Farmdoc's Premium Estimator for available insurance policies for several states and important grain crops in the U.S. (http://www.rma.usda.gov/policies/2006policy.html; http://www.farmdoc.uiuc.edu/cropins/index.html).
} 
the gross herd offtake rate, $\widetilde{o}_{\text {ilt }}$ (which includes slaughters, sales, transfers out, etc.) and the herd mortality rate, $\tilde{M}_{i l t}$.

Pastoralists consume a great portion out of their own herd each season in this region, e.g., either through direct slaughtering or off-taking of herd. We thus reflect this very key feature by including a subsistent consumption constraint $c \geq H^{c}$. And so from the herd growth dynamics, this subsistent consumption constraint thus implies that that each season $H^{c}$ is at least a required seasonal livestock offtake level that covers the minimum consumption required for every household member. In this model, we assume households have identical membership structures and thus $H^{c}$ is the same for each household.

Herd reproduction, mortality and herd offtake and recruitment decisions also depend on the risks inherent in the system. The main covariate component in household asset risk is related to rangeland conditions, and so is characterized by the vegetation index $n d v i_{l t}$ that follows probability distribution $f\left(n d v i_{l t}\right)$. This covariate risk is covered by IBLI. But each household also faces risks, $\varepsilon_{i l t}$, drawn from probability distribution $h\left(\varepsilon_{i l t}\right)$, that are uncorrelated with the covariate component and therefore uncovered by IBLI. This latter component includes mainly idiosyncratic shocks experienced by specific households - such as conflict, raiding, predation, accidents, etc. - as well as other covariate risk unrelated to range conditions - such as disease outbreaks - although we find the latter is relatively small compared to the covariate component. Together these processes generate the net stochastic herd growth rate in period $t$, which nets out herd offtake and mortality rates from the reproduction and herd recruitment rates so that the seasonal herd accumulation can be characterized by

$$
\widetilde{H}_{i l t+1}=\left(\begin{array}{l}
\left.1+\widetilde{b}_{i l t}\left(n d v i_{l t}, \varepsilon_{i l t}, H_{i l t}\right)+{\widetilde{i_{i l t}}}_{\left(n d v i_{l t},\right.}, \varepsilon_{i l t}, H_{i l t}\right) \\
-\operatorname{Max}\left\{\widetilde{o}_{i l t}\left(n d v i_{l t}, \varepsilon_{i l t}, H_{i l t}\right), \frac{H^{c}}{H_{i l t}}\right\}-\widetilde{M}_{i l t}\left(n d v i_{l t}, \varepsilon_{i l t}\right)
\end{array}\right) \cdot H_{i l t}
$$


where the stochastic herd size $\widetilde{H}_{i l t+1}$ is realized at the end of period $t$. The reproduction and net offtake rates vary with a household's beginning herd size, $H_{\text {ilt }}$. Note that we abstract here from modeling each of these livestock reproduction and transaction choices; instead we simply calibrate this growth function based on the household-specific longitudinal data.

The stochastic net growth function (e.g., $\widetilde{b}_{i l t}+\widetilde{i}_{i l t}-\widetilde{o}_{i l t}-\widetilde{M}_{i l t}$ ) defined in equation (3) is assumed to be continuous, equal to zero when the beginning herd size is zero and bounded from below at zero. Equation (3) thus implies nonlinearities in herd accumulation due to the consumption requirement, $\mathrm{H}^{c}$, which imposes a fixed cost rate inversely proportional to the beginning herd size on the rate of return on livestock assets. Given the fixed subsistence consumption requirement, households with smaller herd sizes must consume a larger portion of their herd. Herd decumulation naturally results where net herd growth falls below the minimum consumption rate.

The resulting nonlinearity in net herd growth imposed by the subsistent consumption constraint thus implies a bifurcation in herd accumulation characterized by at least one (subsistence-driven) threshold $H^{*}\left(H^{c}\right)$ above which herd size is expected to evolve toward a high-level equilibrium and below which it is expected to fall to a poverty trap equilibrium. Equation (3) can therefore be rewritten as a nonlinear net herd growth function $\eta(\cdot)$ such that the expected net herd growth conditional on herd size bifurcates at the critical herd threshold $H^{*}\left(H^{c}\right)$ :

$$
\begin{array}{r}
\widetilde{H}_{\text {ilt }+1}=\eta\left(n d v i_{l t}, \varepsilon_{\text {ilt }}, H_{\text {ilt }}\right) \quad \text { where } \quad E \eta_{H_{\text {ilt }}}^{\prime}(\cdot)<0 \text { if } H_{\text {ilt }}<H^{*}\left(H^{c}\right) \\
E \eta_{H_{\text {ilt }}}^{\prime}(\cdot) \geq 0 \text { if } H_{\text {ilt }} \geq H^{*}\left(H^{c}\right) .
\end{array}
$$

Setting the subsistence consumption level at 0.5 TLU per season per household, ${ }^{4}$ Figure 2 illustrates the nonlinear expected net herd growth estimated nonparametrically ${ }^{5}$

\footnotetext{
${ }^{4}$ Previous survey work in this region finds average livestock offtake for household consumption averages slightly less than one goat a month (McPeak 2004). According to FAO (1992), five goats (each yielding 20 kilograms of meat equivalent to 5000 grams of protein) gives an average family of three 46 grams of protein per day per individual, nearly the recommended daily intake of 50 grams of protein per day per individual.

${ }^{5}$ The function is estimated using Epanechnikov kernel with rule-of-thumb optimal bandwidth.
} 
using observed household herd data (birth, mortality, purchase, exchange, sale, slaughter and transfer rates) in 2000-2002 and 2007-2008. This pattern implies the bifurcated herd threshold at around 15 TLU per household - consistent with previous findings (Lybbert et al. 2004, McPeak 2004, Barrett et al. 2006, Santos and Barrett 2007, 2011) - below which herds collapse over time toward a stable equilibria of 0 TLU, implying an exit from pastoralism. Above that threshold, herds grow toward a high-level stable equilibrium size of 55-60 TLU.

\section{[FIGURE 2 ABOUT HERE]}

With a subsistent consumption constraint $c \geq H^{c}$, household $i$ then derives intertemporal utility based on a simplified constant relative risk aversion (CRRA) function defined over livestock wealth as

$$
\begin{array}{rlrl}
U\left(H_{i l t}, \widetilde{H}_{i l t+1}\left(H_{i l t}\right), \ldots, \widetilde{H}_{i l t+\tau}\left(H_{i l t}\right), \ldots\right) & =E^{t}\left(\sum_{\tau=t}^{\infty} \delta^{\tau-t} u\left(H_{i l \tau}\right)\right) \\
\text { where } & u\left(H_{i l \tau}\right) & =\frac{\widetilde{H}_{i l \tau}^{1-R_{i}}}{1-R_{i}}
\end{array}
$$

$0<R_{i} \leq 1$ is the Arrow-Pratt coefficient of relative risk aversion and $\delta \in(0,1)$ is the discount factor. Because of the direct link between herd and welfare dynamics, the certainty equivalent growth rate of stochastic herd dynamics provides a direct household welfare measure. Define the certainty equivalent herd growth rate as the constant net herd growth rate with respect to the initial herd, $H_{\text {ilt }}$, that yields the same intertemporal utility as the expected intertemporal utility obtained from the stochastic herd dynamics. Specifically, the certainty equivalent growth rate, $\eta_{i l}^{c}$, of the stochastic herd dynamics, $\left\{\widetilde{H}_{i l \tau}\right\}_{\tau=t+1}^{T}$, can be written as ${ }^{6}$

$$
U\left(\eta_{i l}^{c} H_{i l t}, \ldots, \eta_{i l}^{c} H_{i l t}\right)=U\left(\widetilde{H}_{i l t+1}\left(H_{i l t}\right), \widetilde{H}_{i l t+2}\left(H_{i l t}\right), \ldots, \widetilde{H}_{i l T}\left(H_{i l t}\right)\right) .
$$

Using this formulation, IBLI increases household welfare if it increases the certainty equivalent herd growth rate relative to that of the uninsured herd dynamics. Therefore, a

\footnotetext{
${ }^{6}$ If $\delta=1$, this can be written more generally as $U\left(\eta_{i l}^{c} H_{i l t}\right)=E U\left(\widetilde{H}_{i l t+\tau}^{I}\left(H_{i l t}\right)\right)$.
} 
risk premium growth rate, $\Delta \eta_{i l}^{c}=\eta_{i l}^{c I}-\eta_{i l}^{c N I}$, provides a measure of dynamic welfare improvement due to insurance. This measure has general applicability to dynamic welfare analysis with respect to any asset insurance.

The certainty equivalent growth rate thereby provides a convenient measure of the intertemporal welfare impact of IBLI given the underlying herd dynamics, in contrast to the existing literature, which concentrates on static impact analysis. ${ }^{7}$ This is important because IBLI performance in the initial insured seasons affects performance in later seasons through the reinforcing impact of herd dynamics where growth patterns are nonlinear. For example, if IBLI fails to protect household from losses in the initial seasons that set it on a herd decumulation trajectory, IBLI's long-term performance could be compromised by the initial herd collapse and ensuing dominant herd dynamics. Because the welfare and growth effects of loss vary depending on where in the herd size distribution one experiences loss, standard insurance performance measures based on induced changes in outcome distributions evaluated at the population means will not suffice in this setting.

\subsection{Managing mortality risk with IBLI}

IBLI compensates for covariate livestock mortality loss based on the predicted herd mortality index in each location, $\hat{M}\left(n d v i_{l t}\right)$. For simplicity, we assume that the household insures either all or none of its herd at the start of each season, which enables us to compare fully insured herds under several contract specifications against the case of no insurance. The insured herd size realized at the end of coverage season $t$ for a household in location $l$ can thus be written as

$$
\widetilde{H}_{i l t+1}^{I}=\left(1+\widetilde{g}_{i l t}\left(n d v i_{l t}, \varepsilon_{i l t}, H_{i l t} \mid H^{c}\right)-\tilde{M}_{i l t}\left(n d v i_{l t}, \varepsilon_{i l t}\right)+\pi_{l t}-\rho_{l t}^{a}\right) \cdot H_{i l t}
$$

where $\widetilde{g}_{\text {ilt }}$ represents the non-mortality component in the net growth rate in (3).

\footnotetext{
${ }^{7}$ Another approach concentrates on measuring changes in the distribution of the insured outcome based on mean-variance measures, e.g., coefficient of variation, value at risk and downside risk measures (Skees et al. 2001; Turvey and Nayak 2003; Vedenov and Barnett 2004). Since that approach ignores the insuree's risk preferences, it may misestimate the benefit of insurance (Fishburn 1977; Breustedt et al. 2008).
} 
IBLI thus reduces expected net herd growth in good seasons by the IBLI premium, $\rho_{l t}^{a}$, but IBLI should at least partially compensate for losses during periods of substantial covariate herd mortality through the indemnity payment, $\pi_{l t}$. Given certain cost and uncertain benefit, the household-specific basis risk with respect to the contract $\left(M^{*}, \hat{M}\left(n d v i_{l t}\right)\right)$ is thus a key determinant of IBLI performance. According to (1) and (7), basis risk depends on the correlation between the predicted area average mortality index, $\hat{M}_{l t}\left(n d v i_{l t}\right)$, and the individual-specific mortality rate, $\tilde{M}_{i l t}\left(n d v i_{l t}, \varepsilon_{i l t}\right)$. The larger the proportion of predictable covariate loss in a household's individual mortality loss, the greater the gains from IBLI.

We further investigate the basis risk in IBLI by disaggregating the householdspecific mortality rate into a beta representation form of the hedgable predicted mortality index. Specifically, household-specific herd mortality $\tilde{M}_{i l t}\left(n d v i_{l t}, \varepsilon_{i l t}\right)$ is orthogonally projected onto the predicted area average mortality index as ${ }^{8}$

$$
\tilde{M}_{i l t}\left(n d v i_{l t}, \varepsilon_{i l t}\right)=\mu_{i l}+\beta_{i}\left(\hat{M}_{l t}\left(n d v i_{l t}\right)-\hat{\mu}_{l}\right)+\varepsilon_{i l t}
$$

where $E\left(\varepsilon_{i l t}\right)=0, \operatorname{Cov}\left(\hat{M}_{l t}\left(n d v i_{l t}\right), \varepsilon_{i l t}\right)=0$ and $\operatorname{Var}\left(\varepsilon_{i l t}\right)=\sigma_{i l}^{2} I$. Here $\mu_{i l}$ reflects household i's long-term average mortality rate, which implicitly reflects householdspecific characteristics that determine their livestock loss (e.g., herding ability), $\hat{\mu}_{l}$ is the long-term mean of the predicted mortality index for location $l$ and $\varepsilon_{\text {ilt }}$ reflects other losses that are not correlated with the covariate component captured by the index.

This beta representation allows us to identify distinct, interrelated householdspecific basis-risk determinants, $\left\{\beta_{i}, \varepsilon_{i l t}, \mu_{i l}\right\}$. The coefficient $\beta_{i}$ measures the sensitivity of the household's mortality experience to the predicted herd mortality index in its area. $\beta_{i}=1$ represents the case in which deviations of household i's livestock losses from its long-term average are, on average, perfectly explained by variations in the predicted area average mortality index, while $\beta_{i}=0$ corresponds to the case, where these two series are independent. If the household-specific mean mortality $\mu_{i l}$ is relatively similar to the

\footnotetext{
${ }^{8}$ Miranda (1991) and Mahul (1999) also use variant of this specification.
} 
location-specific mean predicted mortality rate $\hat{\mu}_{l}$, then the closer $\beta_{i}$ is to one, the better will the predicted mortality index explain household's losses, and so the lower the basis risk. Pastoralists with $\beta_{i}$ lower (greater) than one or with $\mu_{i l}$ lower (greater) than $\hat{\mu}_{l}$ therefore tend to over (under)- insure their herd mortality losses using IBLI, and so they end up paying higher (lower) prices for IBLI that offer unnecessary (insufficient) compensation for their losses, on average. The risk component $\varepsilon_{\text {ilt }}$ reflects the relative proportion of household's overall losses that are not manageable by IBLI. The greater its variance, $\sigma_{i l}^{2}$, the larger the basis risk.

Our analytical framework thus emphasizes the standard theoretical result that the risk management effectiveness of any IBLI contract specification, $\left(M^{*}, \hat{M}\left(n d v i_{l t}\right), \rho_{l t}^{a}\right)$, measured by $\Delta \eta_{i l}^{c}=\eta\left(n d v i_{l t}, \beta_{i}, \varepsilon_{i l t}, \mu_{i l}, H_{i l t}, R_{i}\right)$ depends on exposure to insurable covariate risk, household-specific variation in these key basis risk determinants and risk preferences. A critical innovation with this approach is that the presence of a thresholdbased poverty trap further implies that IBLI performance also depends on household herd size.

\subsection{Threshold-based IBLI performance}

Holding risk preferences and basis risk determinants constant, Appendix 1 shows analytically that the dynamic welfare effect, and consequently the household's valuations of IBLI vary with initial herd size in the presence of bifurcated asset dynamics. ${ }^{9}$ In particular, we show that four distinct cohorts could emerge.

(I) For the poorest households whose herd sizes are too far beneath the critical herd size threshold, IBLI cannot alter herd dynamics. IBLI only provides typical insurance in reducing the probability of herd loss during a bad season, while the premium payment speeds up herd decumulation during good seasons. These poorest households'

\footnotetext{
${ }^{9}$ We note that we abstract from the very real possibility that IBLI induces a change in households' investment behavior, for the simple reason that without any prior observation of IBLI, or some other form of insurance, we have no firm empirical basis for specifying such behavioral responses. Since IBLI could induce either increased investment in livestock by making them a less risky asset or decreased investment in livestock if households were engaged in precautionary savings in kind to deal with uninsured risk exposure, it is unclear what bias, if any, is introduced by this assumption of no investment response.
} 
IBLI valuation would thus be the same as that in the standard insurance case without bifurcated asset dynamics. However, since households in this cohort converge to the lowlevel equilibrium with or without insurance, IBLI offers them relatively little in the way of economic relief. Other instruments are better suited to meet their needs.

(II) Those households whose herd sizes are just marginally above the herd threshold expect to grow their herds if the season is good and if they do not pay the insurance premium. For these households, paying the insurance premium may actually drop them below the threshold. Consequently, IBLI can have adverse consequences to herd growth dynamics for this subpopulation. The value of IBLI is therefore lower than it would be absent the bifurcated herd dynamics, holding risk preferences and basis risk constant.

(III) Vulnerable households are those whose herd sizes are modestly above, but still vulnerable to the risk of falling below, the critical herd threshold. IBLI can protect vulnerable households from falling below the poverty trap threshold in the wake of adverse insured shocks. IBLI can thus offer especially favorable dynamic impacts by keeping the household on its herd growth trajectory. IBLI therefore increases this subpopulation's insurance valuation relative to the case without bifurcated asset dynamics.

(IV) For the non-poor households with herd sizes so large that even without insurance they are not expected to fall below the critical herd threshold after covariate shocks, IBLI would not alter their herd dynamics, just as was the case with the first cohort (with the smallest herds). But because these larger herd sizes can enjoy higher expected net herd growth, which IBLI compensation could preserve in the event of a payout, their valuation of IBLI is significantly more than those in the first cohort.

Overall, cohorts three and four - the wealthier segments of this at-risk population - could represent the main source of demand for IBLI in this setting. The first two cohorts could also benefit from IBLI, but perhaps only with significant subsidies to the cohort approaching the herd size threshold from below, and with virtually free insurance for the very poor. Such policy options are discussed in detail later in the paper. 


\section{Empirical estimation and simulation}

We simulate households' herd dynamics and key performance determinants - household risk preferences and basis risk - as a first step towards exploring the effectiveness of IBLI contracts over many sets of seasons, with different initial seasonal outcomes. The main component in estimating and simulating herd dynamics is the net herd growth rate in (3). We estimate the non-mortality component separately from the mortality component as we are particularly interested in estimating the key basis risk determinants directly from the correlations between individual households' livestock mortality and the location-specific predicted herd loss index that triggers IBLI payout.

We first estimate the non-mortality component of the seasonal livestock growth function in (3) with a subsistence consumption of 0.5 TLU per household per season. We pool four seasons of herd dynamics data from 2000-2002 and two seasons from 20072008 under the maintained hypothesis that the expected herd growth function is stable across 2000-2008. Kernel-weighted local polynomial regression ${ }^{10}$ is used to estimate two nonparametric relationships between the non-mortality herd growth rates ${ }^{11}$ and household beginning TLU herd size conditional on whether the observed season is good or bad, as defined by seasonal NDVI data according to Chantarat et al. (2013). The two estimated non-mortality growth functions conditional on the vegetation condition are then used in the simulation of herd dynamics. They are plotted in Appendix 2.

Next, we estimate the relationship between household-specific herd mortality rates and the location-average predicted mortality index described in (8). We pool four seasons of household-specific mortality rates across the four 2000-2 study locations. A linear relationship between deviations of the two from their long-term means is then estimated using a random coefficient model with random effects on the slope coefficient, commonly known as "beta".

\footnotetext{
${ }^{10}$ An Epanechnikov kernel function is used and the optimal bandwidth is chosen according to Silverman's rule of thumb.

${ }^{11}$ Growth rates were constructed using observations on births, purchases, borrowing and lending of animals, exchanges, sales, slaughters and transfers.
} 
This model, estimated by maximum likelihood, allows us to take into account variation in slope coefficients across households. ${ }^{12}$ The estimated slope coefficient represents the degree of sensitivity of household's mortality loss to the predicted covariate mortality index for their location. Of course there may still be other covariatebut-unpredicted components, in addition to the idiosyncratic component, in the model's disturbances, which can potentially result in cross-sectional correlation. In an attempt to disaggregate these two components in the disturbances, the predicted seasonal householdspecific residual $\hat{\varepsilon}_{i l t}$ is projected onto its location-specific mean each season, $\bar{\varepsilon}_{l t} \cdot{ }^{13}$ So the model we estimate can be summarized as

$$
\begin{aligned}
\tilde{M}_{i l t}\left(n d v i_{l t}, \varepsilon_{i l t}\right)-\mu_{i l} & =\beta_{i}\left(\hat{M}_{l t}\left(n d v i_{l t}\right)-\hat{\mu}_{l}\right)+\varepsilon_{i l t} \\
\varepsilon_{i l t} & =\beta_{i}^{\varepsilon} \bar{\varepsilon}_{l t}+e_{i l t}
\end{aligned}
$$

where $\beta^{\varepsilon} \bar{\varepsilon}_{l t}$ represents the covariate component in the unpredicted mortality loss with degree of co-variation measured by $\beta^{\varepsilon}$, and $e_{i l t}$ represents household's idiosyncratic mortality loss with $E\left(e_{i l t}\right)=0, E\left(e_{i l t} e_{j l t}\right)=0$ if $i \neq j$, and $\operatorname{Var}\left(e_{i l t}\right)=\sigma_{i l}^{2} I$. The estimation results, which allow us to estimate household's basis-risk-determining parameters and other key characteristics ${ }^{14}$ in $\left\{\beta_{i}, \varepsilon_{i l t}, \mu_{i l}, H_{i l t}, \beta_{i}^{\varepsilon}, e_{i l t}\right\}$, are reported in Appendix 2.

We show in Figure 3 the distributions of estimated household betas, as well as the unpredicted component of mortality losses, $\varepsilon_{i l t}$ for these four locations. ${ }^{15}$ Overall, the beta distribution centered around 0.8 with considerable variation, ${ }^{16}$ ranging from -0.35 to 2

\footnotetext{
${ }^{12}$ Estimation of models of beta-representation (e.g., the CAPM model in financial econometrics) generally rely on the seemingly unrelated regressions model for sector-specific equations, which allows for unrestricted error structures (e.g., due to potentially cross-sectional correlations). In our case, we do not have enough longitudinal observations of individual households to apply that model.

${ }^{13}$ The intercept for this model is zero by construction.

${ }^{14}$ The overall average herd sizes observed from 2000-2002 and 2007-2008 are used as representatives of the beginning herd sizes in the four locations.

${ }^{15}$ Though our estimations and simulations from this point on were location-specific, we report overall results. Some location-specific results are reported in the Appendices; the rest can be requested from the lead author.

${ }^{16}$ Because the first equation in (16) implies the estimated household beta only with respect to the hedgable mortality index, this does not have to be centered at one, unlike the estimated household beta with respect to area-average losses - such as is commonly used in agricultural finance literature for measuring basis risk
} 
with a standard deviation of 0.5. The distribution of the mean-zero unpredicted component of mortality losses also exhibits high variation, ranging from -0.42 to 0.44 with a standard deviation of 0.12 . This dispersion indicates considerable basis risk in IBLI in spite of the product's very strong out-of-sample performance (Chantarat et al. 2013), and the potential for significant, predictable variation in performance across households.

\section{[FIGURE 3 ABOUT HERE]}

We then estimate parametrically the best-fit joint distributions, by location, of the estimated household-specific characteristics $\left\{\beta_{i}, \varepsilon_{i l t}, \mu_{i l}, H_{i l t}, \beta_{i}^{\varepsilon}, e_{i l t}\right\}$ using the@Risk program, which allows us to specify a correlation matrix that captures pairwise relationships between these variables, and the upper and lower limits of the distributions. The best-fit distributions were then chosen based on the $\chi^{2}$ goodness of fit criterion. The estimation results are reported in Appendix 3.

Using these estimated distributions, we then simulate herd dynamics of 500 representative households in each location as follows. For each location, we randomly draw 500 combinations of household-specific $\left\{\beta_{i}, \beta_{i}^{\varepsilon}, \mu_{i l}, H_{i l t}\right\}$ from the joint distributions - each of which represents a simulated representative household. For each simulated household, we then randomly draw 54 seasons of idiosyncratic components of mortality loss, $e_{i l t}$, from the location-specific distribution. ${ }^{17}$ We also randomly draw 54 seasons of location-average unpredicted mortality losses, $\bar{\varepsilon}_{l t}$, from the values estimated according to (9).

Figure 4 presents the overall cumulative distributions of baseline household herds (i.e., without insurance) during various years for these four locations. More than $50 \%$ of herds collapse toward destitution over time in Dirib Gombo, compared to less than 10\% in North Horr, reflecting the relatively low beginning herd sizes and high seasonal mortality experience in Dirib Gombo relative to other locations. The bifurcated livestock

of area yield insurance (Carter et al. 2007; Miranda 1991). In contrast, the estimated $\beta_{i}^{\varepsilon}$ is centered at one by construction.

${ }^{17}$ We use the location-specific distribution of $e_{i l t}$ since we do not have enough individual data to simulate the individual-specific distributions. 
growth in the simulated herd dynamics can be shown by simply estimating the autoregression in (4) for 10-season (5-year) lags. Figure 5 plots the results, which clearly display a critical herd size threshold around 15 TLU.

\section{[FIGURE 4 and 5 ABOUT HERE]}

We also simulate dynamics for 15 stylized pastoralist households with key characteristics, e.g., five different beginning TLU herd sizes $\{5,10,15,20,30\}$ and three levels of beta coefficients $\{0.5,1,1.5\}$ for each initial herd size. Each is assumed to have a long-term mortality rate that resembles the location-specific long-term mean predicted mortality index, and a location-specific uncovered risk component. These stylized households allow us to better understand how basis risk and initial herd sizes influence IBLI's impact on herd dynamics.

We are now ready to analyze the effectiveness of IBLI by simply comparing herd dynamics with and without IBLI. We construct 54 pseudo sets of 54 consecutive seasons from the existing vegetation data letting each observation serve as an initial period once in a revolving 54-season sequence with the working assumption that these 54 seasons repeat themselves in sequence. ${ }^{18}$ This allows us to evaluate performance of IBLI taking into account different possible initial realizations of stochastic range conditions.

We consider five IBLI contracts with five strike levels of five percent increments from $10-30 \%$. Households are assumed to insure their entire herd. For each contract, we simulate the resulting insured herd dynamics based on (7) using the distribution of location-specific seasonal predicted mortality index $\hat{M}\left(n d v i_{l t}\right)$ and the location-specific premium rate shown in Table 2 .

As we compute the value of insurance based on the expected utility approach, the certainty equivalent herd growth depends on household discount rates and risk preferences. For simplicity, we assume no discounting, $\delta=1$. We calibrate householdspecific CRRA parameters based on a simple Binswanger lottery game run among the

\footnotetext{
${ }^{18}$ This is a harmless assumption. In essence, the typical burn rate approach to weather insurance evaluation assumes that one year is statistically independent of another and that the universe of possibilities is contained within the historical timeframe represented by the data. Thus in probability the likelihood of 54 seasons repeating in sequence is the same as any other sequence of 54 non-repeating seasons.
} 
households in June-July 2008 (Chantarat et al. 2009). ${ }^{19}$ For each location, we then randomly assign each simulated household with one of the six CRRA parameters based on the observed wealth strata specific distributions of CRRA.

\section{The effectiveness of IBLI for managing livestock asset risk}

Figure 6 depicts some key patterns of insured herd dynamics, using the Kargi location and $\beta=1$ as an example. Panels (a) to (e) each reflect the cumulative distributions of uninsured and insured herd sizes for a single household over a set of 54 simulated seasons.

\section{[FIGURE 6 ABOUT HERE]}

Panel (a) shows that IBLI does little for pastoralists with a low beginning herd size (e.g., 5 TLU). IBLI cannot prevent these households from falling into destitution given how far they are beneath the critical herd growth threshold ( 15 TLU). Indeed, paying an insurance premium each season without offsetting indemnities slightly accelerates herd collapse. ${ }^{20}$

Varying patterns of IBLI performance emerge for pastoralists with herd sizes around the critical herd threshold, i.e., for those whose herd dynamics are very sensitive to shocks. Panel (b) represents a pastoralist with an initial herd size of 15 TLU immediately at or slightly below the critical threshold. This pastoralist was hit by large covariate shocks that so disrupted his asset accumulation that he ended on a decumulating growth path without insurance. But with IBLI imperfectly compensating for the losses, decumulation was averted, and the result was a stabilized growth trajectory. Because IBLI changes his herd dynamics by insuring against catastrophic collapse, the

\footnotetext{
${ }^{19}$ Households were first given $100 \mathrm{Ksh}$ for participating. Then we introduced five lotteries, which vary by risk and expected return. Respondents were invited to use their $100 \mathrm{Ksh}$ to play one of the five lotteries for a real prize, if they wished. If they decided to pay $100 \mathrm{Ksh}$ to play, they were then asked to choose their most preferred lottery to play. A fair coin was then tossed to determine their prize. Six categories of risk aversion associated with six (geometric mean) coefficients of relative risk aversion were derived based on households' choices. Appendix 5 summarizes the results of this risk preference elicitation experiment.

${ }^{20}$ Our model assumes away possible indirect benefits of IBLI, such as its potential to crowd in finance for ancillary investment and growth. If IBLI crowds in credit access, it may alter the growth trajectory and the critical herd size threshold, opening up the possibility that IBLI benefits the least well-off pastoralists as well. Our data do not permit credible parameterization of such shifts, so we abstract from them in this analysis.
} 
certainty equivalent herd growth associated with IBLI should be relatively high due to the added effect of the bifurcated herd dynamics in the system.

Panel (c) presents the opposite case, in which a pastoralist with the same initial herd size of 15 TLU could slowly climb onto the herd growth trajectory during good vegetative seasons if he did not pay an IBLI premium. If his luck holds, he could escape the poverty trap without IBLI; the premium payments in this case actually retard progress. The difference between panels (b) and (c) purely reflect the ex-post effects due to random draws of seasonal condition and reflect the great value of insurance when it proves to have been needed, and also the adverse effects of premium payments on those who enjoyed a streak of good luck.

Panel (d) presents the case of a pastoralist with 20 TLU, who would be vulnerable to shocks that could knock him onto the decumulation trajectory in the absence of effective insurance. We see that for vulnerable households just above the critical herd size threshold, well-designed IBLI can effectively move them away from the poverty trap, substantially lessening the probability of herd size collapse. This is the population that benefits most, in expectation, from IBLI.

Panel (e) depicts the common pattern of IBLI performance for pastoralists with large initial herd sizes - e.g., $30 \mathrm{TLU}$ - who face little immediate danger of falling into destitution. IBLI contracts provide typical insurance, reducing the probability of herd losses, while seasonal premium payments also reduce the chance of reaching extremely large herd sizes. This simply reflects the second-order stochastic dominance of the insured herd sizes relative to the uninsured.

The ex ante wealth impacts on IBLI performance shown in Figure 6, however, holds constant other household- and location-specific characteristics that determine a household's basis risk exposure associated with IBLI. ${ }^{21}$ We now consider the performance of actuarially fair IBLI contracts conditional on contract specifications and household characteristics. Table 3 reports the change in certainty equivalent herd growth rate (also referred to as the positive risk premium growth rate) associated with IBLI for

\footnotetext{
${ }^{21}$ And so it is possible for some pastoralists with as high as 40 TLU to still be vulnerable to shock, and so can benefit greatly from IBLI in preserving their growth trajectory.
} 
15 stylized households (with individual mean mortality fixed at the location-averaged mean predicted mortality index) in each of the four locations. ${ }^{22}$ Various results emerge.

\section{[TABLE 3 ABOUT HERE]}

First, we observe that IBLI performance varies with beginning herd sizes, confirming the patterns shown in Figure 6. IBLI gains are negligible for pastoralists with the lowest herd sizes (5 TLU) and highest for those with the herd sizes around the critical herd threshold (e.g., 15-20 TLU). IBLI does not seem well suited for the poorest herders whose low endowments leave them trapped by the underlying dynamics of the system rather than by uninsured risk exposure. By contrast, those with marginally viable herd sizes are especially susceptible to shocks thus insurance is potentially of considerable benefit to them.

Second, IBLI performance tends to improve as beta increases, holding other things equal. This implies that over-insuring tends to have far larger adverse impact on herd dynamics than does underinsuring. Indeed, IBLI typically benefits most those with beta $=1.5$ rather than those whose herd sizes tend to move one-for-one with local averages. Households with greater-than-average risk exposure (e.g., beta $>1$ ) find IBLI especially valuable, despite only-partial coverage from IBLI.

Finally, these simulations suggest that the IBLI contract with a $10 \%$ strike level outperforms other contracts, on average, even though the $10 \%$ strike contract is more costly than the others. The greater protection apparently is worth it given the risk of falling beneath the critical herd size threshold. This effect is most pronounced for those with initial herd sizes just above the threshold (at $20 \mathrm{TLU}$ ), whose vulnerability to shocks is best addressed with a low strike insurance contract.

Having observed how variations in household-specific characteristics could affect individual-level IBLI performance, we now explore how the observed location-specific distributions of those characteristics affect IBLI performance at a more aggregate scale. Table 4 first reports the overall performance of actuarially fair IBLI contracts among 2000 simulated pastoralists across the four locations.

\footnotetext{
${ }^{22}$ For simplicity, Table 3 only reports certainty equivalent results calculated with respect to a CRRA value of 0.7. Results for other degrees of CRRA are similar and are available by request. Location-specific results are available by request.
} 


\section{[TABLE 4 ABOUT HERE]}

The $10 \%$ strike contract appears to have the highest performance holding other things equal. On average, actuarially fair IBLI contracts with a $10 \%$ strike level result in a $17 \%$ increase in the long-term mean herd size, and a reduction in downside risk of $12 \% .{ }^{23}$ On average, certainty equivalent herd growth increases only modestly with increasing risk aversion.

In general, effective demand for IBLI (e.g., positive risk premium herd growth rate) exists in all locations for IBLI contracts with less than a 30\% strike, with the highest demand for the $10 \%$ strike contract. But not everyone benefits. Figure 7 presents the cumulative distributions of the improvement in certainty equivalent growth rates with respect to three different IBLI contracts in these four locations. At least half the households benefit from an IBLI contract with a 10\% strike (slightly lower proportions for other strike levels) with the positive risk premium growth rates associated with the contract ranging up to almost $100 \%$. The distribution of valuations for the $10 \%$ contract clearly dominates that of the other contracts in these locations.

[FIGURE 7 ABOUT HERE]

\section{Willingness to pay and potential demand for IBLI}

The preceding analysis offers a glimpse into prospective demand patterns for IBLI. So far, we have explored the performance of IBLI contracts sold at actuarially fair premium rates. But an insurer needs to add a commercial loading. This will change the impact of IBLI on herd dynamics by changing the premium paid for insurance. We can use this same simulation model to estimate demand for IBLI by searching for the $\rho_{l t}^{a}$ that drives the risk premium growth rate to zero. In this section, we explore demand for the $10 \%$ strike IBLI contract previously shown to have the greatest expected benefit for most pastoralists in the region.

\footnotetext{
${ }^{23}$ These two measures are used widely in the mean-variance evaluation approach of agricultural insurance. Downside risk reduction is measured by semi-variance reduction of the insured herd dynamics with IBLI relative to the uninsured herd. Specifically, semi-variance of the insured herd dynamics over a set of consecutive seasons $t, \ldots, T$, denoted by $\left\{\widetilde{H}_{i l \tau}^{I}\right\}_{\tau=t+1}^{T}$, relative to some threshold, for example, household's long-term mean herd size $\bar{H}_{i l}$, can be well written as $S V_{\bar{H}_{i l}}\left(\widetilde{H}_{i l \tau}^{I}\right)=\operatorname{EMax}\left(\bar{H}_{i l}-\widetilde{H}_{i l \tau}^{I}, 0\right)^{2}$.
} 
We first estimate the maximum willingness to pay (WTP) for IBLI of each simulated pastoralist by searching for the maximum premium loading (a) according to (2) that still yields a non-negative risk premium growth rate. The expected maximum willingness to pay conditional on household initial herd size is then estimated nonparametrically across 2000 simulated pastoralists. The average herd-conditional WTP is shown in Figure 8, plotted against the observed herd size distribution.

\section{[FIGURE 8 ABOUT HERE]}

WTP for IBLI above the actuarially fair rate is only attained at herd sizes of at least 15 TLU, just around the threshold at which herd dynamics bifurcate. Since most households' herds fall below the threshold level, this implies limited potential demand for even actuarially fairly priced IBLI. Expected WTP increases at an increasing rate for those with herd sizes between 15-20 TLU and then continues to increase significantly toward its peak at an average 18\% loading at the herd sizes around 40 TLU - just below the high-level herd size equilibrium - after which there is no statistically significant change in WTP as herd size increases. The clear implication is that WTP may not be high enough for a commercially viable IBLI absent subsidies to induce uptake.

Based on these estimated distributions of households' WTP for IBLI in each location, we now study potential aggregate demand. Specifically, we construct a districtlevel aggregate demand curve for Marsabit District as follows. Assuming that the 2000 simulated households in the four study locations are randomly drawn from the total population of 27,780 households in 28 locations in Marsabit District, ${ }^{24}$ we treat each simulated household as representing approximately 14 households in the district population. We then order the WTP across the population and plot the premium loadings (a) against the cumulative herd sizes of the population whose WTP would support commercial demand at that loading level.

Figure 9 displays the estimated aggregate demand curve for IBLI in Marsabit District and disaggregates it for each of three herd size groups: (i) the low herd group (with $<10 \mathrm{TLU}$ ) representing the $26 \%$ of the population that currently finds itself on a herd decumulation trajectory into a stockless poverty trap, (ii) vulnerable pastoralists

\footnotetext{
${ }^{24}$ Per the Administrative Census of Marsabit district (1999) produced by Kenya National Bureau of Statistics and International Livestock Research Institute.
} 
(with 10-30 TLU) representing the 47\% of the population who risk collapsing into the poverty trap with the next uninsured shock to their herd size, and (iii) the better off pastoralists (with $>30 \mathrm{TLU}$ ) who represent the $27 \%$ of population that control most of the district's livestock herd and who, in the absence of an unusually severe shock or series of such shocks, should be secure.

\section{[FIGURE 9 ABOUT HERE]}

Aggregate demand for IBLI seems very price elastic with reduction in quantity demanded by $55 \%$ as the fair premium rate is loaded by $20 \%$, and a further $26 \%$ reduction with an additional $20 \%$ premium loading. If the commercially viable IBLI contract rate is set at a $20 \%$ loading, these highly elastic aggregate demand patterns show potential aggregate demand of approximately 210,000 TLU in Marsabit District alone. These patterns highlight several points. First, relatively large herd owners will be the key drivers of a commercially sustainable IBLI product. Second, the apparent price elasticity of demand in these locations implies that a small premium reduction (e.g., through subsidization) can potentially induce large increases in quantity demanded. For example, as Figure 9 shows, a decrease in premium loading from $40 \%$ to $20 \%$ could potentially induce more than a doubling of aggregate demand. Third, while IBLI appears most valuable for the most vulnerable pastoralists (those with herd sizes around 10-30 TLU) as it could protect their herd dynamics from catastrophic shock, most of their WTP lies well below the commercially loaded IBLI premium (i.e., at least a 20\% loading). This, as we showed in Figure 6 panel (c), is due to the possibility that high premium payments will impede herd accumulation across the herd growth threshold.

Premium subsidization may therefore be important if it is socially desirable to stimulate IBLI uptake among vulnerable populations. Might IBLI subsidies provide a cost-effective and productive safety net in broader social protection programs sponsored by governments or donors? That is the final question we explore using these simulation models. 


\section{Enhancing productive safety nets using IBLI}

In order to investigate whether IBLI subsidies might effectively provide a productive safety net for pastoralists in northern Kenya, we first explore herd and poverty dynamic outcomes (using an asset poverty line of $10 \mathrm{TLU}$ ) of these 2000 simulated pastoralists under four different scenarios: (i) without insurance, (ii) with commercially loaded IBLI (assuming a $20 \%$ premium), (iii) with an optimally targeted premium subsidization scheme that maximizes asset poverty reduction outcomes, and (iv) with comparable, needs-based subsidization targeted to the poorest households with less than 20 TLU.

The targeted premium subsidization scheme is optimized by searching for the combination of subsidized premium rates targeted to different herd groups - (a) the poorest ( $<10 \mathrm{TLU})$, (b) the non-poor likely to fall into poverty in the longer run $(10-20$ TLU), (c) the vulnerable non-poor (20-30 TLU), (d) the secure pastoralists (30-50 TLU) and (e) the large-scale pastoralists with $>50$ TLU - that yields the lowest poverty outcomes. The results (details available from the lead author by request) imply that the optimal premium subsidization scheme would provide IBLI free to group (b) and at the actuarially fair premium rate for the vulnerable non-poor groups (c) and (d), with no subsidization to groups (a) and (e). We compare this with two needs-based schemes: subsidized to the fair rate $(a=0 \%)$ and free provision targeted to the less well off pastoralists with herd sizes less than 20 TLU.

In each of these scenarios, the simulated household herd at the end of each season reflects the household's optimal insurance choice - i.e., insure if (induced) WTP exceeds the (subsidized) premium rate, do not insure otherwise. Therefore, the herd outcomes for the case of strictly commercial IBLI, for example, largely represent the outcomes of the insured herds of the well off pastoralists who demand WTP even at commercial rates and the uninsured herds of the rest of the population. Figure 10 depicts these herd dynamic outcomes in the form of mean household herd size and asset poverty $(<10$ TLU) headcount measures estimated from the 2000 simulated household over the 54 seasons of available NDVI data, 1982-2008.

[FIGURE 10 ABOUT HERE] 
The commercially loaded IBLI without subsidization, which only attracts a majority of the well-off pastoralists, has very limited effect on poverty. Average herd sizes under this scenario closely track the no-insurance case, with only modest increases largely among insured, well-off pastoralists partially protected from shocks by IBLI.

By contrast, under the optimal subsidy scheme, mean herd sizes increase more than $80 \%$, relative to the no insurance case, over the course of a quarter century. Likewise, the asset poverty headcount decreases slightly over time and stabilizes at a level about 10\% lower than without insurance. Subsidized IBLI protects many targeted pastoralists herds against collapse beneath the critical growth threshold.

The most distributionally progressive, strictly need-based schemes achieve less than half of these optimal outcomes. While they follow similar (herd size increasing and poverty decreasing) patterns, we still observe increasing poverty headcounts even with free IBLI for the poorest. This simply reflects the fact that IBLI provides little benefit for pastoralists with low herd sizes or with high basis risk exposure. Perhaps counterintuitively, allocating scarce resources to subsidize the vulnerable non-poor may do more to keep long-term poverty headcount rates down than allocating the same resources to the poorest. $^{25}$

In this simple simulation, the average cost of the optimal targeted subsidization scheme, which reaches $20 \%-50 \%$ of the population over 54 historical seasons, is roughly $\$ 50$ per beneficiary per six-month season. ${ }^{26}$ This implies a $\$ 20$ per capita cost per one percent reduction in the poverty headcount rate, in contrast to $\$ 38$ for the needs-based scheme. An effective safety net can be both cheaper and more effective in stemming long-run poverty than traditional transfer programs (Barrett et al. 2012).

\section{Conclusions}

Covariate livestock mortality is a key source of vulnerability among east African pastoralists and often drives households into extreme persistent poverty. In the presence of poverty traps resulting from well-documented nonlinear herd growth dynamics in the

\footnotetext{
${ }^{25}$ Barrett et al. (2012) demonstrate similar results in a more general setting.

26 One TLU is valued at $12,000 \mathrm{Ksh}$, approximately $\$ 160$ based on October 2009 exchange rates $(75.05 \mathrm{Ksh} / \mathrm{US} \$)$.
} 
region, effective risk management becomes potentially important as a means of reducing long-term poverty rates. This paper offers novel dynamic estimates of the welfare effects of an index-based livestock insurance (IBLI) product expressly developed to address this problem and first implemented in Marsabit district of northern Kenya in early 2010.

Our analysis adds to the current literature because of our focus on asset risk rather than income risk - and the existence of bifurcated asset dynamics in the northern Kenyan pastoral system. These two characteristics require important innovations in ex ante impact assessment of insurance. We develop a dynamic simulation model and a modified expected utility-based evaluation criterion in order to take into account the potential dynamic impact of IBLI. We use household-level parameter estimates including household-specific risk preferences elicited from field experiments as well as basis risk parameters estimated from panel data from the region to explore a) key patterns of variation in IBLI performance, b) patterns of willingness to pay, and c) the aggregate demand for IBLI.

We find that household initial herd size - i.e., ex-ante wealth - is the key determinant of IBLI performance, more so than household risk preferences or basis risk exposure. IBLI works least well for the poorest, whose meager endowments effectively condemn them to herd collapse given prevailing herd dynamics. By contrast, IBLI is most valuable for the vulnerable non-poor, for whom insurance can stem collapses onto a trajectory of herd decumulation following predictable shocks.

We find that a $10 \%$ strike contract consistently outperforms higher strike level contracts. District-level aggregate demand appears highly price elastic with potentially limited demand for contracts with commercially viable premium loadings. Because willingness to pay is especially price sensitive among the most vulnerable pastoralists (i.e. those not currently caught in a poverty trap, but on the verge of falling into one) for whom the product is potentially most beneficial, subsidization of asset insurance as a safety net intervention may prove worthwhile. Simple simulations find that relatively inexpensive, partial subsidization targeted to households with herd sizes in specific ranges can significantly increase average wealth and decrease poverty, at a rate of just $\$ 20$ per capita per one percent reduction in the poverty headcount rate. 
The operational costs of implementing a program of targeted subsidies may be quite considerable, however. Indeed, the cost of identifying the households to be targeted under the optimal subsidy scheme as presented in the previous section may prove prohibitive. Identifying recipient households may be easier for the distributionally progressive scheme providing subsidies for households with less than 20TLUs, but would require a universal livestock census of the target areas. While the census exercise may be costly, it would have benefits beyond IBLI subsidy targeting to include, inter alia, improved efficiency of veterinary service provision and vaccination campaigns, support to anti-stock theft policies and their enforcement, the implementation of standards regimes across the value chain, and the increased ease of asset taxation and monitoring market transactions. We therefore emphasize that our findings abstract from practical considerations of policy implementation and are meant to stimulate careful thought about the most effective, as well as implementable, means to address insurable risk and its relationship to poverty in the pastoralist areas of east Africa.

Our key result is also that IBLI will be less valuable to the poorest whose assets are too small relative to the critical threshold and whose herd decumulation therefore cannot not be altered through IBLI alone. In order to make IBLI work as economic development tool, promotion of IBLI might need to be complemented by promotion of asset accumulation programs. This could include targeted asset transfer programs to first move the poor toward the critical herd size threshold. They could also include expanding access to credit, the introduction of risk mitigating interventions and other efforts that would effectively lower the asset bifurcation threshold. With these longer-term adjustments, IBLI might become more valuable to the poorest as well. 


\section{References}

Barr A. Risk Pooling, Commitment, and Information: An experimental test of two fundamental assumptions. Center for the Study of African Economics, Oxford University; 2003.

Barnett B.J, Barrett C.B, Skees J.R. Poverty Traps and Index-Based Risk Transfer Products. World Development 2008; 36(10); 1766-1785.

Barnett B.J, Mahul O. Weather Index Insurance for Agriculture and Rural Areas in Lower Income Countries. American Journal of Agricultural Economics 2007; 89(5); 1241-1247.

Barrett C.B, Carter M.R, Ikegami M. Poverty Traps and Social Protection. Working paper, Cornell University, University of Calfornia-Davis and International Livestock Research Institute; 2012.

Barrett C.B, Chantarat S, Gebru G, McPeak J.G, Mude A.G, Vanderpuye-Orgle J, Yirbecho A.T. Codebook for Data Collected under the Improving Pastoral Risk Management on East Africa Rangelands (PARIMA) Project. Unpublished, Cornell University; 2008.

Barrett C.B, Marenya P.P, McPeak J.G, Minten B, Murithi F.M, Oluoch-Kosura W, Place F, Randrianarisoa J.C, Rasambainarivo J, Wangila J. Welfare Dynamics in Rural Kenya and Madagascar. Journal of Development Studies 2006; 42(2); 248-277.

Barrett C.B., Santos, P. "The Impact of Changing Rainfall Variability on ResourceDependent Wealth Dynamics," Ecological Economics, forthcoming.

Binswanger H. Attitudes toward risk: Experimental Measurement in Rural India. American Journal of Agricultural Economics 1980; 62; 395-407.

Binswanger H. Attitudes toward risk: Theoretical Implications of an Experiment in Rural India. Economic Journal 1981; 91; 867-890.

Binswanger-Mkhize, H. Is There Too Much Hype about Index-based Agricultural Insurance? The Journal of Development Studies. 2012; 48(2); 187-200

Breustedt G, Bokusheva R, Heidelbach O. Evaluating the Potential of Index Insurance Schemes to Reduce Crop Yield Risk in an Arid Region. Agricultural Economics 2008; 59(2).

Carter M.R, Galarza F, Boucher S. Underwriting Area-based Yield Insurance to Crowdin Credit Supply and Demand. Savings and Development 2007; 31(3); 335-362.

Chantarat S, Mude A.G, Barrett C.B, Carter M.R. Designing Index Based Livestock Insurance for Managing Asset Risk in Northern Kenya. Journal of Risk and Insurance 2013: 80 (1): 205-37. 
Chantarat S, Mude A.G, Barrett C.B. Willingness to Pay for Index Based Livestock Insurance: Results from A Field Experiment in Northern Kenya. Working Paper, Cornell University; 2009.

Dave C, Eckel C, Johnson C, Rojas C. Eliciting Risk Preferences: When is Simple Better? Journal of Risk and Uncertainty; 2010, 41: 219-243,

Deng X, Barnett B.J, Vedenov D.V, West J.W. Hedging Dairy Production Losses Using Weather-based Index Insurance Agricultural Economics 2007; 36(2); 271-280.

Fishburn P.C. Mean-Risk Analysis with Risk Associated with Below Target Returns. American Economic Review 1977; 67(2);116-126.

Food and Agriculture Organization of the United Nations (FAO). Meat and Meat Products in Human Nutrition in Developing Countries. Food and Nutrition Paper 1992; 53.

Little P.D, McPeak J.G, Barrett C.B, Kristjanson P. Challenging Orthodoxies: Understanding Poverty in Pastoral Areas of East Africa. Development and Change 2008; 39(4); 587-611.

Lybbert T.J, Barrett C.B. Risk Taking Behavior in the Presence of Nonconvex Asset Dynamics. Economic Inquiry; 2011, 49(4), 982-988.

Mahul O. Optimum Area Yield Crop Insurance. American Journal of Agricultural Economics 1999; 81; 75-82

McPeak J.G. Contrasting Income Shocks with Asset Shocks: Livestock Sales in Northern Kenya. Oxford Economic Papers 2004; 56; 263-284.

Miranda M. J. Area-Yield Crop Insurance Reconsidered. American Journal of Agricultural. Economics 1991; 73; 233-254

Sandford S. Too Many People, Too Few Livestock: The Crisis Affecting Pastoralists in the Greater Horn of Africa. Future Agricultures Consortium debate. Brighton: Institute of Development Studies, University of Sussex; 2006.

Santos P, Barrett C.B. Heterogeneous Wealth Dynamics: On the Roles of Risk and Ability. Working paper, Cornell University; 2006.

Santos, P., Barrett, C.B. Persistent Poverty and Informal Credit, Journal of Development Economics, 2001; 96(2), 337-347.

Skees J.R, Gober S, Varangis P, Lester R, Kalavakonda V, Kumako K. Developing rainfall-based index insurance in Morocco. World Bank Policy Research Working Paper 2001.

Turvey C.G, Nayak G. The semivariance-minimizing hedge ratio. Journal of Agricultural and Resource Economics 2003; 28; 100-11 
Woodard, J.D., Garcia,P, Basis Risk and Weather Hedging Effectiveness, Agricultural Finance Review, 2008;68(1);99 - 117

Vedenov D.V, Barnett B.J. Efficiency of weather derivatives for agricultural risk management. Journal of Agricultural and Resource Economics 2004; 29; $387-$ 403.

Table 1: Descriptive Statistics, 2000-02 and 2007-08

\begin{tabular}{|c|c|c|c|c|c|c|c|c|c|c|}
\hline \multirow[t]{3}{*}{ Variables/Location } & \multirow{2}{*}{\multicolumn{2}{|c|}{ Overall }} & \multicolumn{8}{|c|}{ Location-Specific } \\
\hline & & & \multicolumn{2}{|c|}{ Dirib Gombo } & \multicolumn{2}{|c|}{ Logologo } & \multicolumn{2}{|c|}{ Kargi } & \multicolumn{2}{|c|}{ North Horr } \\
\hline & Mean & S.D. & Mean & S.D. & Mean & S.D. & Mean & S.D. & Mean & S.D. \\
\hline \multicolumn{11}{|l|}{ Climate } \\
\hline Annual Rainfall $(\mathrm{mm})$ & 290 & 185 & 366 & 173 & 297 & 137 & 270 & 115 & 227 & 86 \\
\hline \multicolumn{11}{|c|}{ Livestock per household, composition and seasonal loss } \\
\hline Livestock in 2008 (TLU) & 15 & 18 & 2 & 4 & 16 & 22 & 17 & 10 & 25 & 19 \\
\hline Camel (\%) & $6 \%$ & $8 \%$ & $0 \%$ & $4 \%$ & $3 \%$ & $9 \%$ & $10 \%$ & $5 \%$ & $9 \%$ & $8 \%$ \\
\hline Cattle (\%) & $14 \%$ & $22 \%$ & $28 \%$ & $34 \%$ & $26 \%$ & $18 \%$ & $2 \%$ & $3 \%$ & $2 \%$ & $3 \%$ \\
\hline Small stock (\%) & $80 \%$ & $21 \%$ & $72 \%$ & $34 \%$ & $71 \%$ & $19 \%$ & $88 \%$ & $6 \%$ & $89 \%$ & $9 \%$ \\
\hline Migration (\%) & $71 \%$ & $38 \%$ & $6 \%$ & $21 \%$ & $87 \%$ & $21 \%$ & $88 \%$ & $16 \%$ & $88 \%$ & $17 \%$ \\
\hline Seasonal livestock loss (\%) & $9 \%$ & $15 \%$ & $3 \%$ & $8 \%$ & $15 \%$ & $22 \%$ & $5 \%$ & $6 \%$ & $11 \%$ & $15 \%$ \\
\hline \multicolumn{11}{|l|}{ Income per capita } \\
\hline Income/day/capita (KSh) & 35 & 89 & 8 & 18 & 32 & 31 & 18 & 28 & 78 & 163 \\
\hline Livestock share (\%) & $59 \%$ & $40 \%$ & $18 \%$ & $31 \%$ & $61 \%$ & $35 \%$ & $87 \%$ & $24 \%$ & $67 \%$ & $34 \%$ \\
\hline \multicolumn{11}{|l|}{ Poverty Incedence } \\
\hline Headcount (1\$/day) & $90 \%$ & & $99 \%$ & & $85 \%$ & & $97 \%$ & & $79 \%$ & \\
\hline Headcount (10 TLU) & $49 \%$ & & $97 \%$ & & $52 \%$ & & $30 \%$ & & $18 \%$ & \\
\hline \multicolumn{11}{|c|}{ Statististics from 2000-2002 data (with catastrophic drought in 2000) } \\
\hline Livestock in 2000 (TLU) & 25 & 28 & 14 & 10 & 19 & 16 & 40 & 45 & 26 & 16 \\
\hline Seasonal livestock loss $(\%)$ & $13 \%$ & $21 \%$ & $21 \%$ & $29 \%$ & $15 \%$ & $19 \%$ & $11 \%$ & $12 \%$ & $7 \%$ & $10 \%$ \\
\hline
\end{tabular}

Note: \% Migration represents the percentage of the household herd that moves at least once over the year. 1 TLU is worth approximately $12,000 \mathrm{KSh}$, equivalent to roughly US\$160 based on October 2009 exchange rates (75.05Ksh/US\$). Income is calculated from the sum of market value of milk and meat production, crop production, livestock trading, business, salary earnings, casual labor wage and other petty trading. 
Table 2: Summary of IBLI Contracts (from Chantarat et al. 2013)

\begin{tabular}{|c|c|c|c|c|c|c|c|c|c|}
\hline \multirow[t]{2}{*}{ Location } & \multicolumn{4}{|c|}{$\begin{array}{l}\text { Predicted Mortality Index } \\
\text { (M) }(\%)\end{array}$} & \multicolumn{5}{|c|}{$\begin{array}{l}\text { Fair Premium Rate (\% Herd Value) } \\
\text { Contract Strike }\end{array}$} \\
\hline & Mean & S.D. & $\mathrm{P}(\mathrm{M}>10 \%)$ & $\mathrm{P}(\mathrm{M}>20 \%)$ & $10 \%$ & $15 \%$ & $20 \%$ & $25 \%$ & $30 \%$ \\
\hline Dirib Gombo & $8 \%$ & $8 \%$ & $28 \%$ & $9 \%$ & $2.5 \%$ & $1.3 \%$ & $0.6 \%$ & $0.3 \%$ & $0.1 \%$ \\
\hline Logologo & $9 \%$ & $8 \%$ & $34 \%$ & $15 \%$ & $3.4 \%$ & $1.8 \%$ & $0.7 \%$ & $0.1 \%$ & $0.1 \%$ \\
\hline Kargi & $9 \%$ & $9 \%$ & $38 \%$ & $11 \%$ & $3.3 \%$ & $1.6 \%$ & $0.9 \%$ & $0.4 \%$ & $0.2 \%$ \\
\hline North Horr & $9 \%$ & $11 \%$ & $34 \%$ & $21 \%$ & $4.3 \%$ & $2.8 \%$ & $1.5 \%$ & $0.7 \%$ & $0.3 \%$ \\
\hline
\end{tabular}

Table 3: Change in Certainty Equivalent Growth Rate, by Household Parameter

\begin{tabular}{|c|c|c|c|c|c|c|c|c|c|}
\hline \multirow{2}{*}{$\begin{array}{c}\text { Strike } \\
\text { Beta }\end{array}$} & \multicolumn{3}{|c|}{$10 \%$} & \multicolumn{3}{|c|}{$20 \%$} & \multicolumn{3}{|c|}{$30 \%$} \\
\hline & 0.5 & 1.0 & 1.5 & 0.5 & 1.0 & 1.5 & 0.5 & 1.0 & 1.5 \\
\hline \multicolumn{10}{|c|}{ Beginning Herd } \\
\hline 5 & $0 \%$ & $0 \%$ & $0 \%$ & $0 \%$ & $0 \%$ & $0 \%$ & $0 \%$ & $0 \%$ & $0 \%$ \\
\hline 10 & $-8 \%$ & $4 \%$ & $11 \%$ & $-1 \%$ & $7 \%$ & $9 \%$ & $-3 \%$ & $-1 \%$ & $0 \%$ \\
\hline 15 & $18 \%$ & $24 \%$ & $40 \%$ & $8 \%$ & $14 \%$ & $23 \%$ & $-1 \%$ & $1 \%$ & $5 \%$ \\
\hline 20 & $9 \%$ & $29 \%$ & $37 \%$ & $8 \%$ & $18 \%$ & $21 \%$ & $0 \%$ & $2 \%$ & $3 \%$ \\
\hline 30 & $2 \%$ & $15 \%$ & $29 \%$ & $2 \%$ & $11 \%$ & $17 \%$ & $-1 \%$ & $0 \%$ & $3 \%$ \\
\hline
\end{tabular}

Note: The cell content reflects the certainty equivalent growth rate of the insured herd dynamics minus that of the uninsured herd dynamics in percentage terms.

Table 4: Simulated IBLI Performance, Four Locations

\begin{tabular}{cccc}
\hline \multicolumn{3}{c}{ Without IBLI } \\
\hline Stat. & Beta & $\begin{array}{c}\text { Beginning } \\
\text { Herd } \\
\text { (TLU) }\end{array}$ & $\begin{array}{c}\text { L-T Mean } \\
\text { Herd } \\
\text { (TLU) }\end{array}$ \\
\hline Mean & 0.8 & 16 & 33 \\
Median & 0.7 & 14 & 31 \\
S.D. & 0.5 & 28 & 30 \\
\hline
\end{tabular}

\begin{tabular}{|c|c|c|c|c|c|c|c|}
\hline \multicolumn{8}{|c|}{ With IBLI } \\
\hline \multirow[t]{3}{*}{ Strike } & \multirow{3}{*}{$\begin{array}{l}\text { Increase } \\
\text { L-T Mean } \\
\text { Herd }(\%)\end{array}$} & \multirow{3}{*}{$\begin{array}{c}\text { Decrease } \\
\text { SV(mean) } \\
(\%) \\
\end{array}$} & \multicolumn{5}{|c|}{ Increase in CER Growth Rate (\%) } \\
\hline & & & \multicolumn{5}{|c|}{ CRRA } \\
\hline & & & 0.9 & 0.7 & 0.4 & 0.1 & Simulated \\
\hline 10 & $17.4 \%$ & $11.7 \%$ & $6.4 \%$ & $6.3 \%$ & $6.0 \%$ & $5.7 \%$ & $6.1 \%$ \\
\hline 20 & $6.7 \%$ & $7.8 \%$ & $2.7 \%$ & $2.5 \%$ & $2.3 \%$ & $2.1 \%$ & $2.5 \%$ \\
\hline 30 & $0.2 \%$ & $0.3 \%$ & $-0.3 \%$ & $-0.4 \%$ & $-0.5 \%$ & $-0.6 \%$ & $-0.4 \%$ \\
\hline
\end{tabular}


Figure 1: Study Areas in Northern Kenya

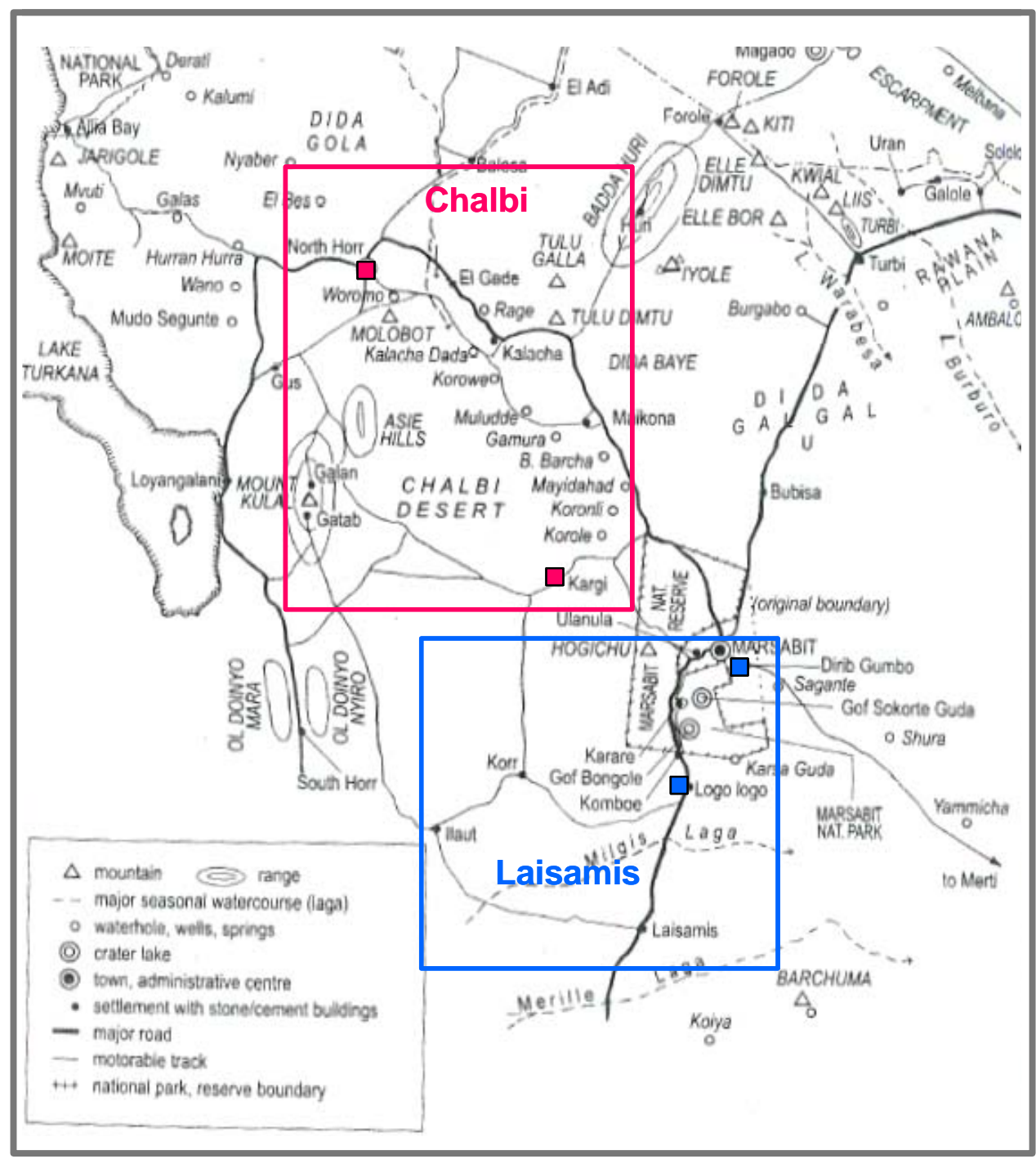


Figure 2: Nonparametric Estimation of Expected Net Herd Growth Rate

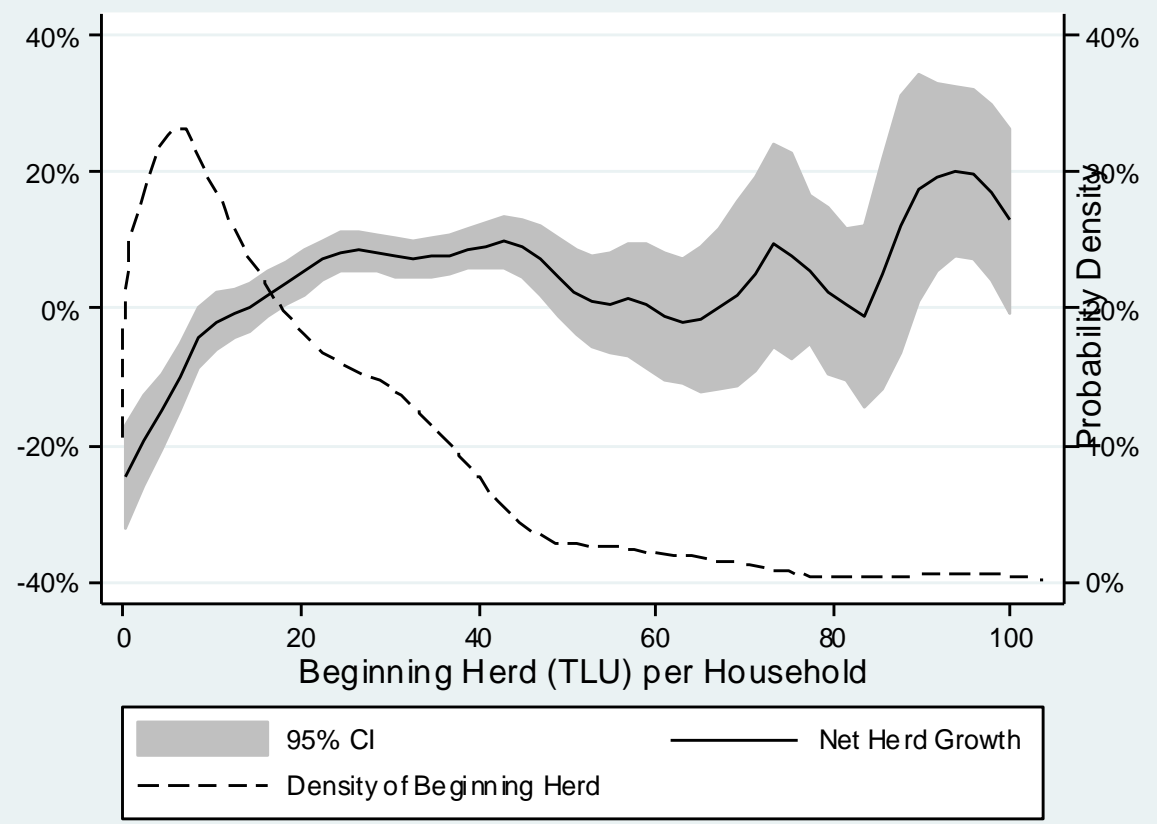

Figure 3: Estimated Household-Specific Beta and Non-Drought-Related Mortality Rate, Random Coefficient Model (2000-2002)
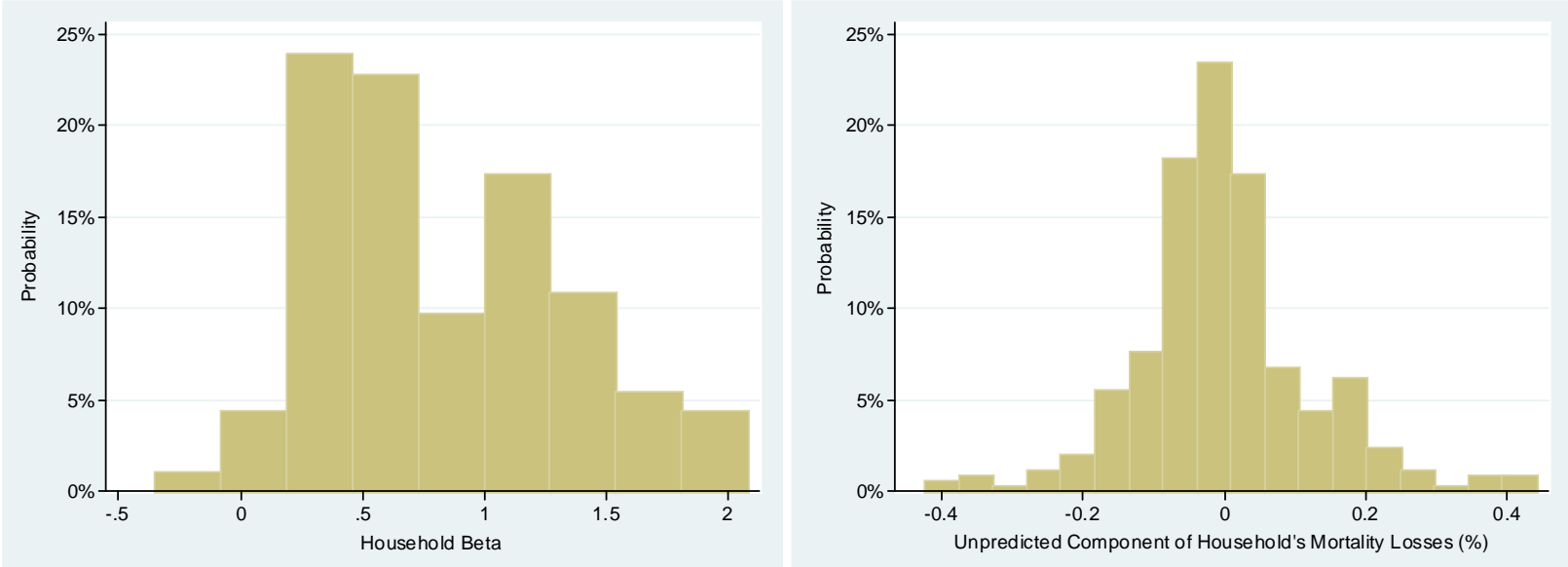
Figure 4: Cumulative Distributions of Simulated Herds by Key Years

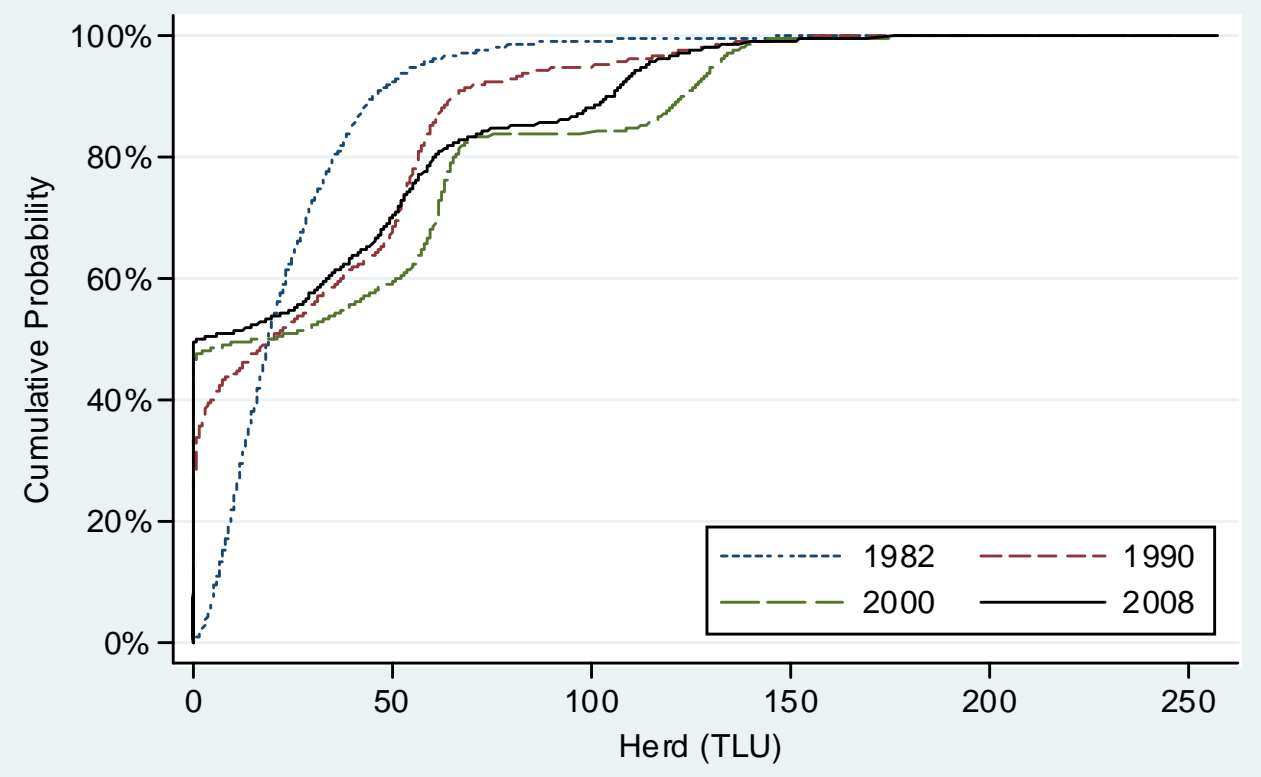


Figure 5: Simulated Herd Accumulation Dynamics, 1982-2008

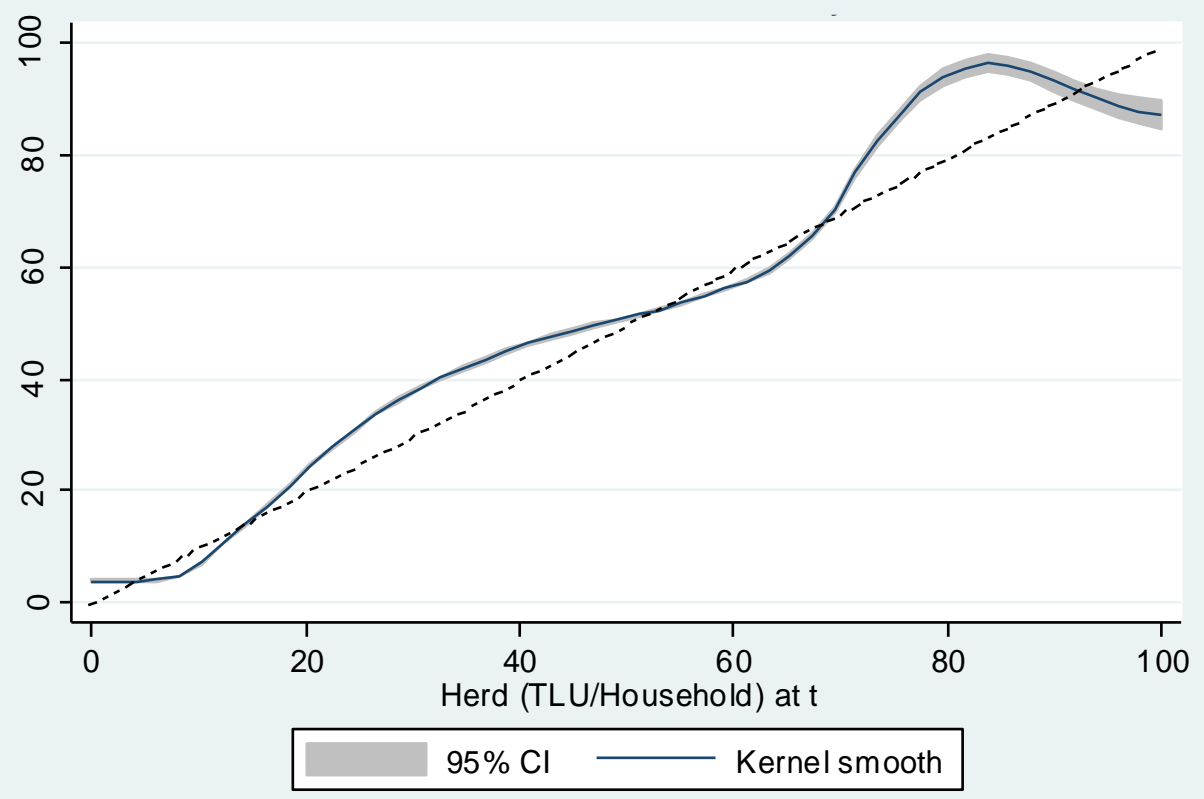




\section{Figure 6: IBLI Performance Conditional on Beginning Herd Size}

\section{(Simulations for Kargi, based on 54 seasons)}
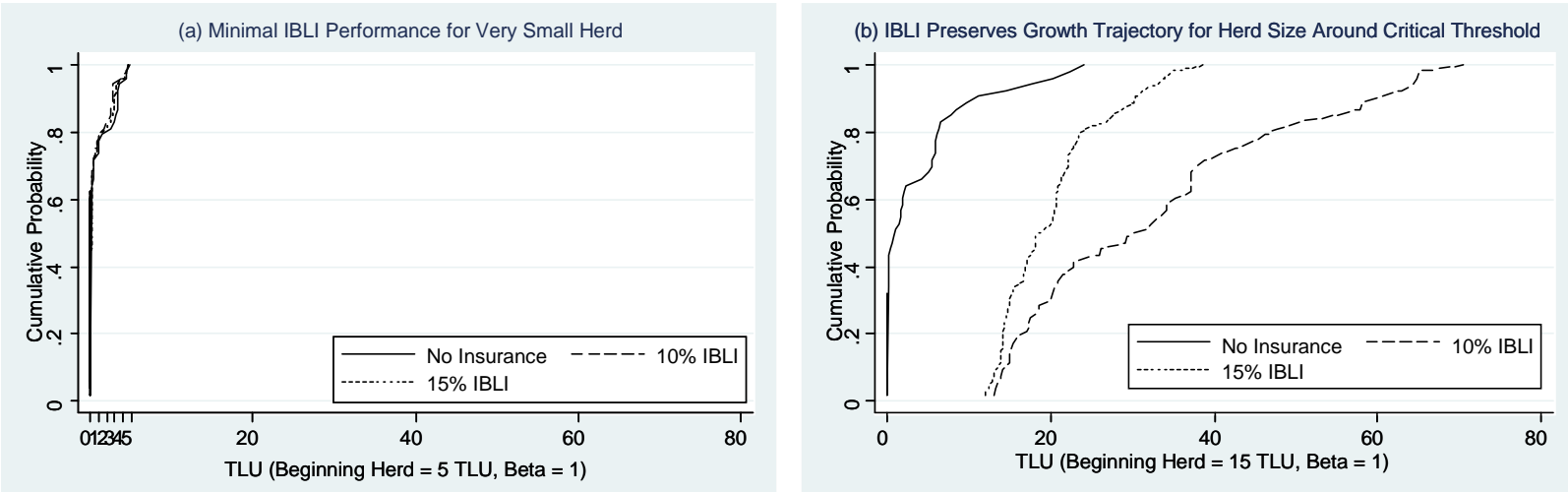

(c) IBLI Reverts Growth Trajectory for Herd Size Around Critical Threshold

(d) IBLI Protects Vulnerable Herd from Falling into Destitution
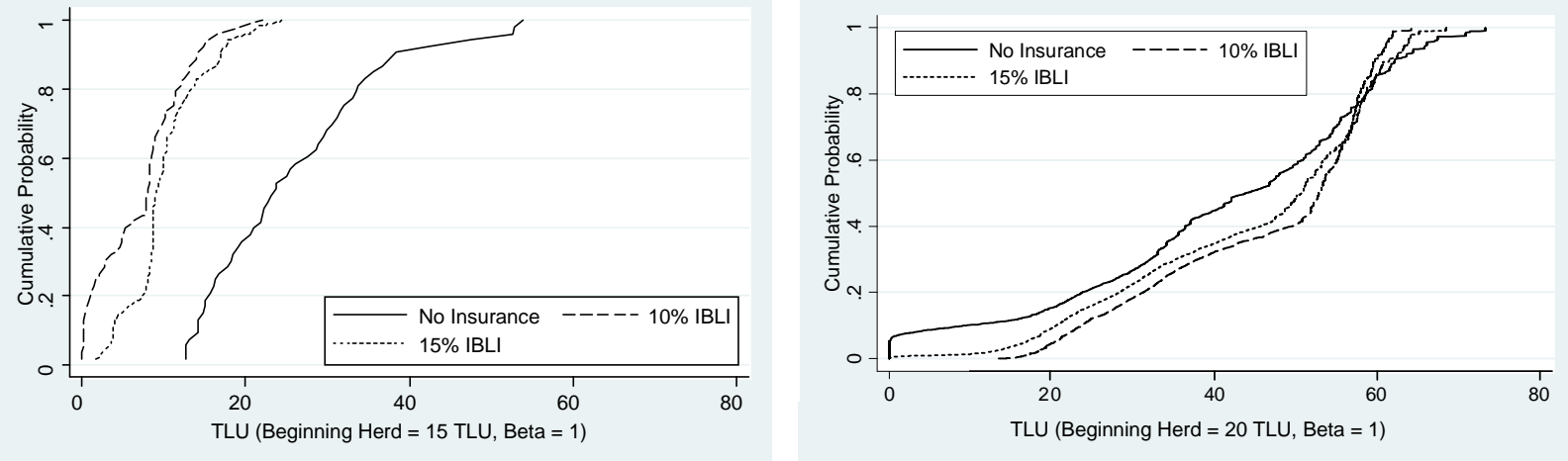

(e) Second-order Stochastic Dominance with IBLI for Large Herd

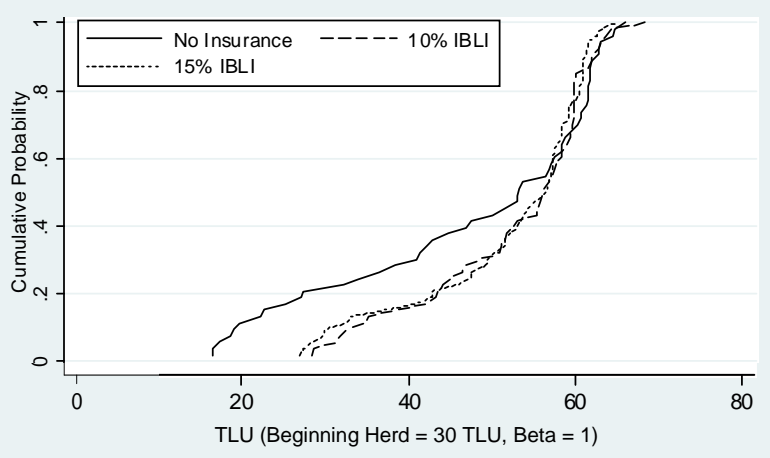


Figure 7: Cumulative Distributions of Change in Certainty Equivalent Growth Rate

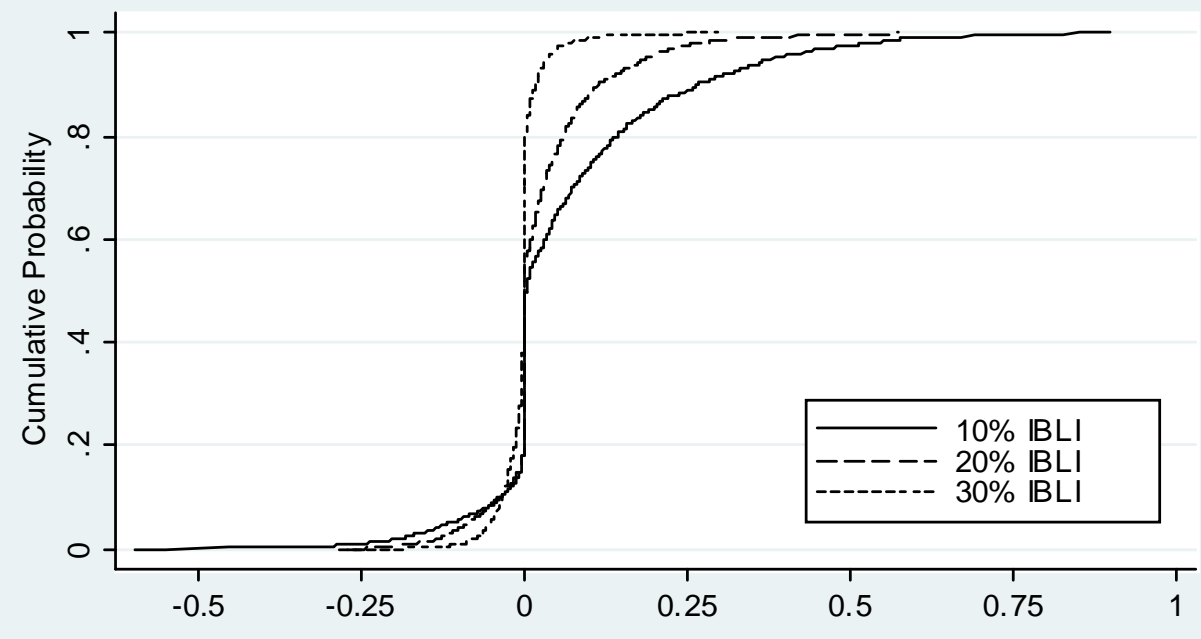

Certainty Equivalent Growth Rate with IBLI (\%) - Certainty Equivalent Growth Rate without IBLI (\%)

Figure 8: Willingness to Pay for IBLI by Initial Herd Size

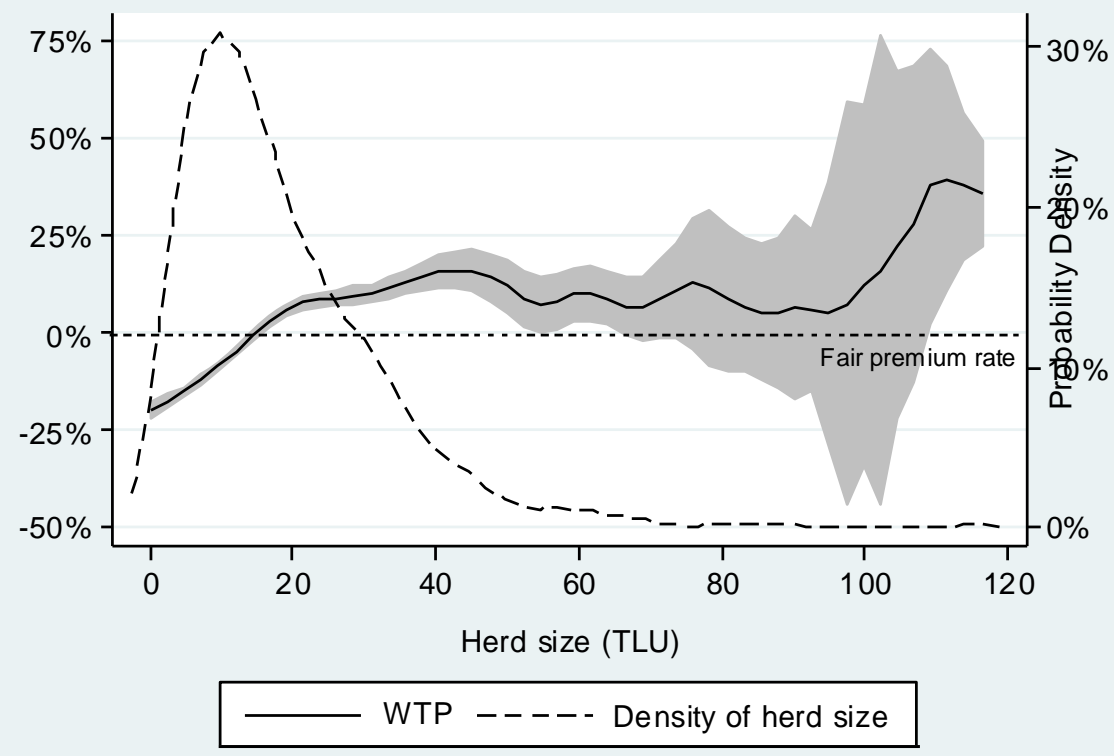


Figure 9: Estimated District-level Aggregate Demand for IBLI

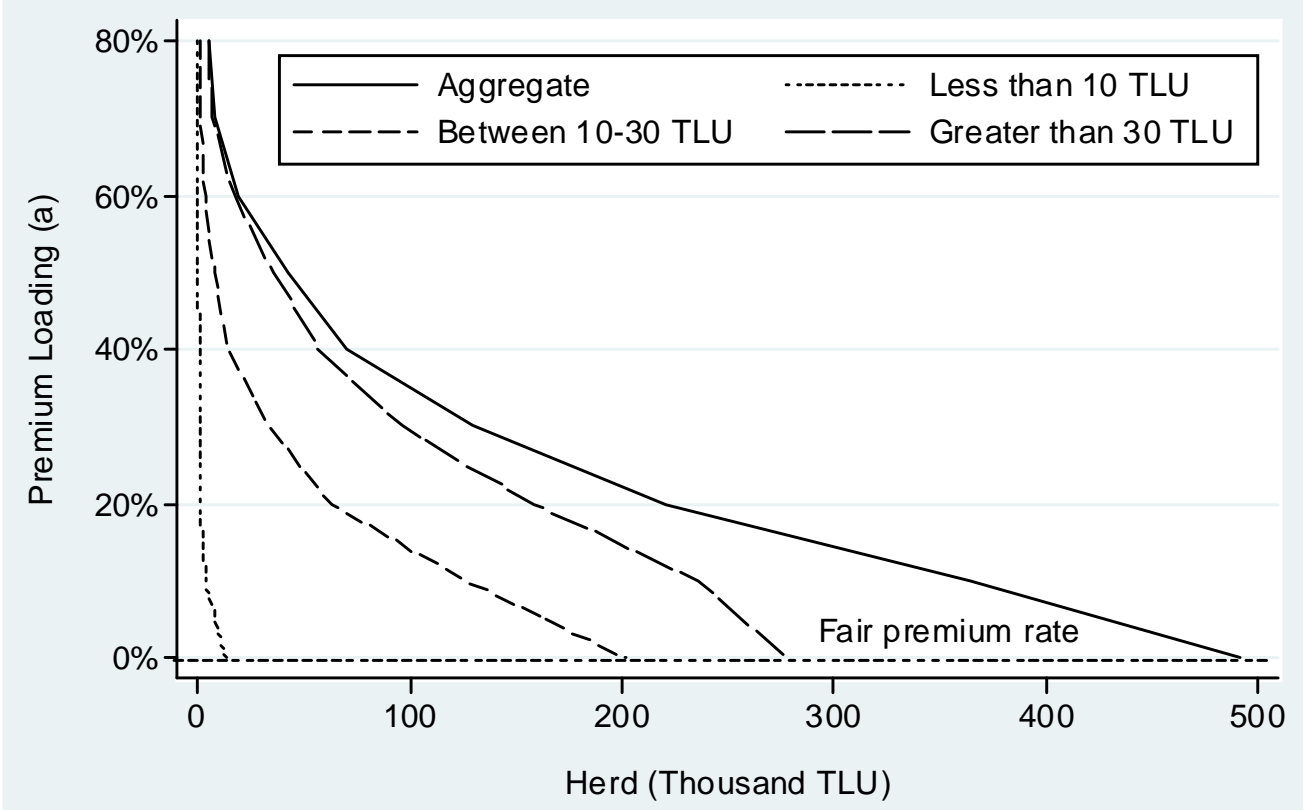


Figure 10: Dynamic Outcomes of Alternative IBLI Subsidy Scheme
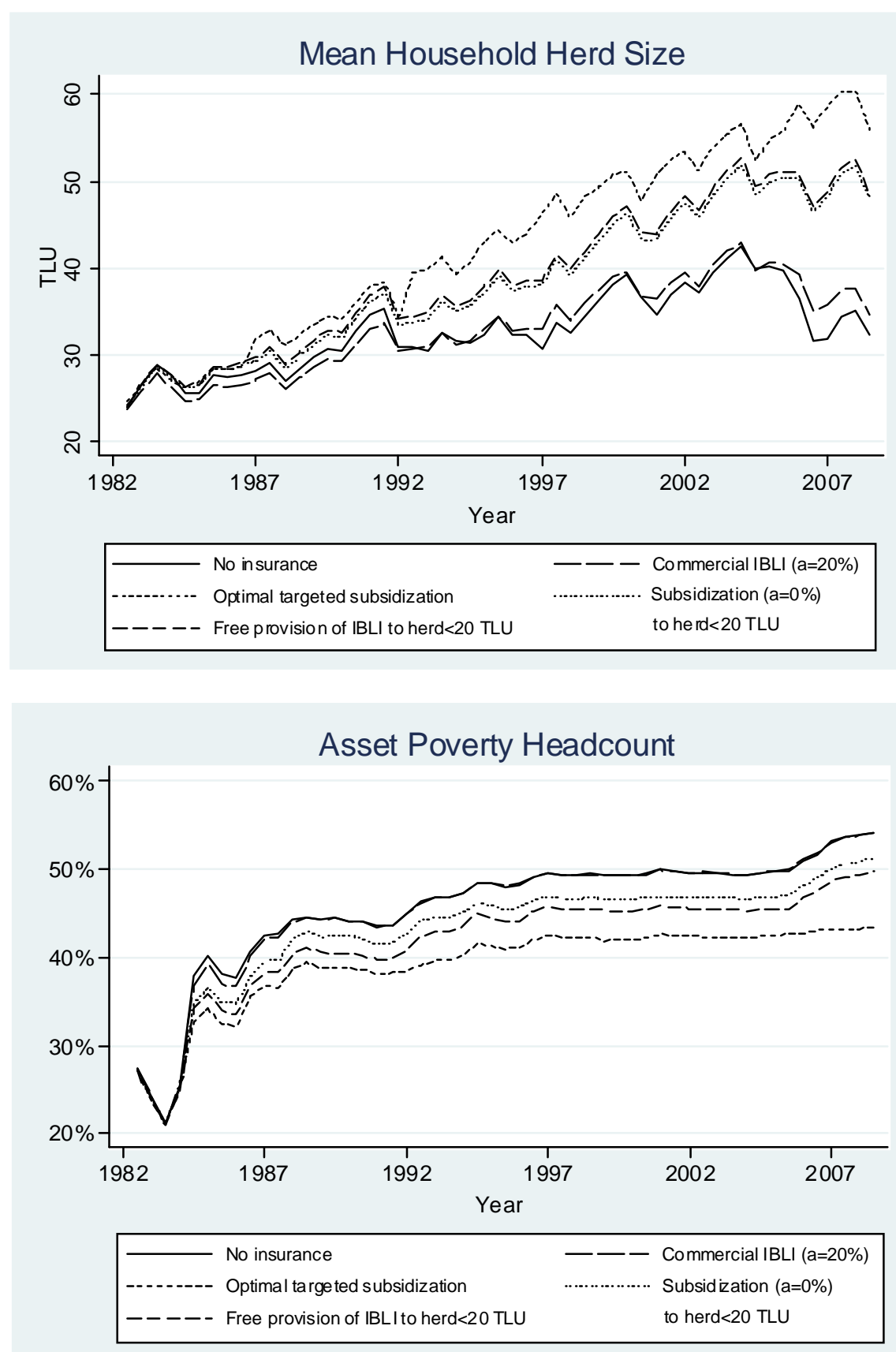


\section{Appendix 1: Threshold-based IBLI Performance}

In order to show analytically how IBLI valuation might deviate from the standard insurance evaluation in the presence of bifurcated asset dynamics, we discretize the nonlinear net herd growth in (4) into a simple additive form:

$$
\begin{aligned}
\text { (A1) } \widetilde{H}_{\text {ilt }+1}=\left(A\left(H_{\text {ilt }}\right)+B\left(n d v i_{l t}, \varepsilon_{\text {ilt }}\right)\right) H_{\text {ilt }} & \text { with } \\
A\left(H_{\text {ilt }}\right) & =\left\{\begin{array}{ll}
n_{L} & \text { if } H_{\text {ilt }}<H \\
n_{H} & \text { if } H_{\text {ilt }} \geq H
\end{array} \text { and } B\left(n d v i_{l t}, \varepsilon_{\text {ilt }}\right)= \begin{cases}\eta_{G}+\varepsilon_{\text {ilt }} & \text { with probability } P \\
\eta_{B}+\varepsilon_{\text {ilt }} & \text { with probability } 1-P\end{cases} \right.
\end{aligned}
$$

In (A1), $A(\cdot)$ represents the deterministic component of the herd growth rate, which is conditional on the initial herd size relative to the critical threshold with $0<\eta_{L}<1$ and $\eta_{H}>1$. The relation $B(\cdot)$ is the stochastic component of herd growth written as the sum of the insurable covariate component captured by NDVI $\left(\eta_{G}>0\right.$ in a good season with probability $P=\int_{0}^{M^{*}} \hat{M}\left(n d v i_{l t}\right) d f\left(n d v i_{l t}\right)$ and $\quad \eta_{B}<0$ in a bad season with probability $(1-P)$ and the uncovered component with $E\left(\varepsilon_{i l t}\right)=0$. Assuming, for simplicity, that $P \eta_{G}+(1-P) \eta_{B}=0$, this implies the expected herd dynamics:

$$
\text { (A2) } \quad E \widetilde{H}_{\text {ilt }+1}=\eta_{i} H_{\text {ilt }} \quad \text { where } \quad \eta_{i}= \begin{cases}n_{L} & \text { if } H_{\text {ilt }}<H^{*} \\ n_{H} & \text { if } H_{\text {ilt }} \geq H^{*}\end{cases}
$$

This allows us to derive recursively two stable intertemporal welfare levels:

$$
U\left(H_{i l t}, H_{i l t+1}\left(H_{i l t}\right), \ldots\right)=\frac{u\left(H_{i l t}\right)}{1-\delta \eta_{i}^{1-R_{i}}} \quad \text { where } \quad \eta_{i}= \begin{cases}n_{L} & \text { if } H_{i l t}<H^{*} \\ n_{H} & \text { if } H_{\text {ilt }} \geq H^{*}\end{cases}
$$

with $0<\eta_{L}<1$ eventually leading those with $H_{\text {ilt }}<H^{*}$ into the poverty trap, a long-run equilibrium herd size close to zero.

We consider the expected impact of IBLI when pastoralists can insure all of their herds at period $t$ with a contract priced at $\rho_{l t}$ that pays $\pi_{l t}$ in a bad season with probability $1-P$ and pays nothing during a good season with probability $P$. Holding risk preferences and basis risk determinants constant, we will show that the dynamic welfare effect of an IBLI contract varies with initial herd sizes at time $t$. In particular, four distinct cohorts emerge. 
(I) For the first cohort, IBLI cannot alter their herd dynamics. Their beginning herd size is too far beneath the critical herd size threshold to grow past $H^{*}$ by the end of the season since even in a good season and without insurance $\left(\eta_{L}+\eta_{G}\right) H_{i l t}<H^{*}$. Thus IBLI only provides typical insurance in reducing the probability of herd loss during a bad season, while the premium payment speeds up herd decumulation during good seasons. By (6), the IBLI valuation is the same as that in the standard insurance case without bifurcated asset dynamics:

$$
\begin{array}{ll}
\frac{u\left(\eta_{i l}^{c N I 1} H_{i l t}\right)}{1-\delta \eta_{L}^{1-R_{i}}}=P \frac{u\left(\left(\eta_{L}+\eta_{G}\right) H_{i l t}\right)}{1-\delta \eta_{L}^{1-R_{i}}}+(1-P) \frac{u\left(\left(\eta_{L}+\eta_{B}\right) H_{i l t}\right)}{1-\delta \eta_{L}^{1-R_{i}}} & \text { w/o IBLI } \\
\frac{u\left(\eta_{i l}^{c I 1} H_{i l t}\right)}{1-\delta \eta_{L}^{1-R_{i}}}=P \frac{u\left(\left(\eta_{L}+\eta_{G}-\rho_{l t}\right) H_{i l t}\right)}{1-\delta \eta_{L}^{1-R_{i}}}+(1-P) \frac{u\left(\left(\eta_{L}+\eta_{B}+\pi_{l t}-\rho_{l t}\right) H_{i l t}\right)}{1-\delta \eta_{L}^{1-R_{i}}} & \text { w/ IBLI }
\end{array}
$$

So

$$
\begin{aligned}
\Delta \eta_{i l}^{c 1}= & \left(P \cdot\left(\eta_{L}+\eta_{G}-\rho_{l t}\right)^{1-R_{i}}+(1-P)\left(\eta_{L}+\eta_{B}+\pi_{l t}-\rho_{l t}\right)^{1-R_{i}}\right)^{R_{i}-1} \\
& -\left(P \cdot\left(\eta_{L}+\eta_{G}\right)^{1-R_{i}}+(1-P)\left(\eta_{L}+\eta_{B}\right)^{1-R_{i}}\right)^{R_{i}-1} .
\end{aligned}
$$

For this cohort, the value of IBLI (reflected in a positive risk premium growth rate) depends on the extent to which IBLI imperfectly compensates for the insured's losses and household-specific risk preferences. However, since households in this cohort converge to the low-level equilibrium with or without insurance, IBLI offers them relatively little in the way of economic relief.

(II) The second cohort consists of pastoralists expecting to grow their herds. Beginning herd sizes are modestly above $H^{*}$ and grow if the season is good and when they do not pay the insurance premium. However, paying the insurance premium drops them beneath $H^{*}$ so that $H^{*}<\left(\eta_{L}+\eta_{G}\right) H_{i l t}<H^{*}+\rho_{l t} H_{i l t 1}$ in a good season. Because IBLI shifts down their herd growth trajectory, the risk premium growth rate is effectively taxed by $\left(\frac{1-\delta \eta_{L}^{1-\theta_{i}}}{1-\delta \eta_{H}^{1-\theta_{i}}}\right)>1$, as is evident from the certainty equivalent growth rate:

$$
\begin{aligned}
& \Delta \eta_{i l}^{c 2}=\left(P \cdot\left(\eta_{H}+\eta_{G}-\rho_{l t}\right)^{1-R_{i}}+(1-P)\left(\eta_{H}+\eta_{B}+\pi_{l t}-\rho_{l t}\right)^{1-R_{i}}\right)^{R_{i}-1} \\
& -\left(\left(\frac{1-\delta \eta_{L}^{1-\theta_{i}}}{1-\delta \eta_{H}^{1-\theta_{i}}}\right) \cdot P \cdot\left(\eta_{H}+\eta_{G}\right)^{1-R_{i}}+(1-P)\left(\eta_{H}+\eta_{B}\right)^{1-R_{i}}\right)^{R_{i}-1}
\end{aligned}
$$


The value of IBLI is therefore lower than it would be absent the bifurcated herd dynamics, holding risk preference and basis risk determinants constant.

(III) The third cohort consists of pastoralists with beginning herd sizes slightly above but still vulnerable to the risk of falling below $H^{*}$. IBLI protects this cohort from falling below $H^{*}$ while their herd size remains above $H^{*}$ after paying the insurance premium, $\left(\eta_{L}+\eta_{G}\right) H_{i l t} \geq H^{*}+\rho_{l t} H_{i l t}$. For them $H^{*}-\left(\pi_{l t}-\rho_{l t}\right) H_{i l t}<\left(\eta_{L}+\eta_{B}\right) H_{i l t}<H^{*}$.

Since IBLI preserves their herd growth trajectory, IBLI increases their insurance valuation relative to the case without bifurcated asset dynamics by the factor $\left(\frac{1-\delta \eta_{H}^{1-R_{i}}}{1-\delta \eta_{L}^{1-R_{i}}}\right)<1$. For this reason, the dynamic welfare impact of IBLI for this cohort is

$$
\begin{aligned}
& \Delta \eta_{i l}^{c 3}=\left(P \cdot\left(\eta_{H}+\eta_{G}-\rho_{l t}\right)^{1-R_{i}}+(1-P)\left(\eta_{H}+\eta_{B}+\pi_{l t}-\rho_{l t}\right)^{1-R_{i}}\right)^{R_{i}-1} \\
& -\left(P \cdot\left(\eta_{H}+\eta_{G}\right)^{1-R_{i}}+\left(\frac{1-\delta \eta_{H}^{1-R_{i}}}{1-\delta \eta_{L}^{1-R_{i}}}\right) \cdot(1-P) \cdot\left(\eta_{H}+\eta_{B}\right)^{1-R_{i}}\right)^{R_{i}-1}
\end{aligned}
$$

(IV) The last cohort consists of pastoralists with herd sizes so large that even without insurance they are not expected to fall below the critical herd threshold after covariate shocks; $\left(\eta_{H}+\eta_{B}\right) H_{i l t} \geq H^{*}$. Thus IBLI would not alter their herd dynamics, just like the first cohort (with the smallest herds). But because these larger herd sizes have higher expected net herd growth, $\eta_{H}$, their valuation of IBLI is significantly more than those in the first cohort according to

$$
\begin{aligned}
\Delta \eta_{i l}^{c 4}= & \left(P \cdot\left(\eta_{H}+\eta_{G}-\rho_{l t}\right)^{1-R_{i}}+(1-P)\left(\eta_{H}+\eta_{B}+\pi_{l t}-\rho_{l t}\right)^{1-R_{i}}\right)^{R_{i}-1} \\
& -\left(P \cdot\left(\eta_{H}+\eta_{G}\right)^{1-R_{i}}+(1-P) \cdot\left(\eta_{H}+\eta_{G}\right)^{1-R_{i}}\right)^{R_{i}-1}
\end{aligned}
$$

Overall, cohorts three and four - the wealthier segments of this at risk population - represent the main source of demand for IBLI in this setting. The expected threshold-based performance of IBLI in the presence of bifurcated wealth dynamics mirrors the patterns found in Lybbert and Barrett (2011) in a different poverty trap model that does not consider insurance options. 


\section{Appendix 2: Non-mortality Component of Herd Growth Function}

Chantarat at al. (2013) defines good seasons as those with positive cumulative deviation of NDVI observed at the end of the season and bad seasons as those with non-positive cumulative deviation of NDVI. Below we plot the two nonparametrically estimated non-mortality growth functions conditional on vegetation conditions, which we use as the basis for the simulations. The conditional herd mortality rates are also plotted here to illustrate that during the good seasons, more households enjoy positive net growth rates (i.e., mortality rate below nonmortality growth rate), while those above the critical herd size threshold of 12-20 animals maintain just slightly above zero growth during the bad seasons. Santos and Barrett $(2007,2011)$ report similar findings in neighboring southern Ethiopia.
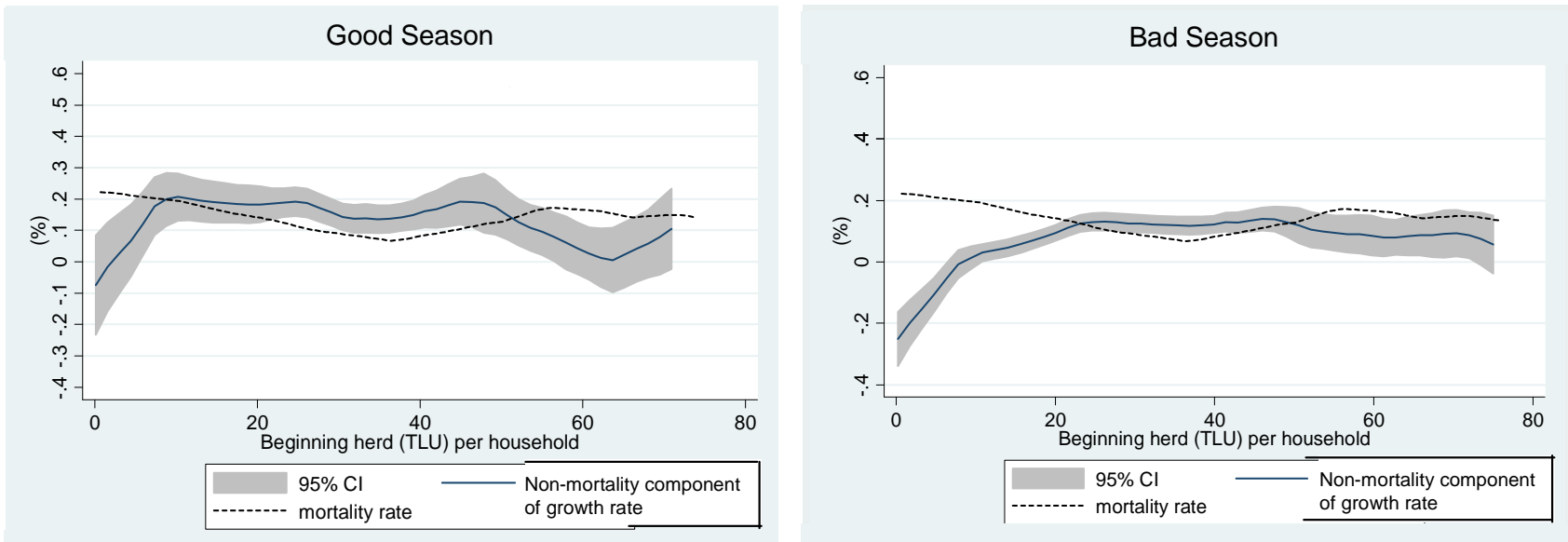


\section{Appendix 3: Summary of Estimated and Simulated Household Characteristics}

Regression of individual mortality on predicted mortality index

\begin{tabular}{|l|l|c|cc|cc|}
\hline Location & \multicolumn{1}{c|}{$\begin{array}{c}\text { Variable } \\
\text { (Best-fit distn) }\end{array}$} & Obs. & \multicolumn{2}{|c|}{ Estimated } & \multicolumn{2}{c|}{ Simulated } \\
\cline { 4 - 7 } & & Mean & S.D. & Mean & S.D. \\
\hline \multicolumn{7}{|l}{ Household-specific $\beta i$} \\
\hline Dirib & ExtValue(0.7,0.6) & 20 & 1.08 & 0.66 & 1.05 & 0.60 \\
Kargi & Logistic $(0.7,0.2)$ & 25 & 0.71 & 0.39 & 0.70 & 0.34 \\
Logologo & Normal $(1.1,0.4)$ & 27 & 1.13 & 0.38 & 1.13 & 0.38 \\
North Horr & Logistic(0.3,0.1) & 22 & 0.37 & 0.18 & 0.36 & 0.16 \\
\hline
\end{tabular}

\begin{tabular}{|l|cc|cc|}
\hline \multirow{2}{*}{ Variable } & \multicolumn{2}{|c|}{ Estimated } & \multicolumn{2}{c|}{ Simulated } \\
\cline { 2 - 5 } & Mean & S.D. & Mean & S.D. \\
\hline Household-specific non-drought related loss $\varepsilon_{\text {ilt }}(\%)$ \\
\hline (Based on the model estimations) & -0.02 & 0.20 & -0.01 & 0.18 \\
& 0.00 & 0.08 & 0.00 & 0.08 \\
& 0.00 & 0.11 & 0.00 & 0.13 \\
& 0.00 & 0.08 & 0.00 & 0.07 \\
\hline
\end{tabular}

Regression of predicted residual on location averaged residual

\begin{tabular}{|l|l|c|cc|cc|}
\hline Location & \multicolumn{1}{|c|}{$\begin{array}{c}\text { Variable } \\
\text { (Best-fit distn) }\end{array}$} & Obs. & \multicolumn{2}{|c|}{ Estimated } & \multicolumn{2}{|c|}{ Simulated } \\
\cline { 4 - 7 } & & Mean & S.D. & Mean & S.D. \\
\hline \multicolumn{7}{|l}{ Household-specific $\beta_{\varepsilon i}$} \\
\hline Dirib & ExtValue(0.6,0.7) & 20 & 1.01 & 0.77 & 1.02 & 0.80 \\
Kargi & Normal $(1,0.3)$ & 25 & 1.00 & 0.27 & 1.01 & 0.26 \\
Logologo & Logistic(1,0.1) & 27 & 1.00 & 0.26 & 1.00 & 0.26 \\
North Horr & ExtValue(0.9,0.2) & 22 & 1.01 & 0.32 & 1.00 & 0.29 \\
\hline
\end{tabular}

\begin{tabular}{|l|ll|ll|}
\hline \multicolumn{1}{|c|}{$\begin{array}{c}\text { Variable } \\
\text { (Best-fit distn) }\end{array}$} & \multicolumn{2}{|c|}{ Estimated } & \multicolumn{2}{c|}{ Simulated } \\
\cline { 2 - 5 } & Mean & S.D. & Mean & S.D. \\
\hline Idiosyncratic loss $\mathrm{e}_{\text {ilt }}(\%)$ & 0.00 & 0.12 & 0.00 & 0.14 \\
\hline LogLogistic(-1,1,17.7) & 0.00 & 0.07 & 0.00 & 0.06 \\
LogLogistic(-0.3,0.3,6.9) & 0.00 & 0.10 & 0.00 & 0.11 \\
LogLogistic(-1.4,1.4,27.1) & 0.00 & 0.04 & 0.00 & 0.04 \\
\hline
\end{tabular}




\section{Other key household characteristics}

\begin{tabular}{|l|l|c|cc|cc|}
\hline Location & Variable & Obs. & \multicolumn{2}{|c|}{ Estimated } & \multicolumn{2}{|c|}{ Simulated } \\
\cline { 4 - 7 } & (Best-fit distn) & & Mean & S.D. & Mean & S.D. \\
\hline Household-specific long-term mean mortality rate $\mu_{\mathrm{il}}(\%)$ \\
\hline Dirib & Logistic(0.2,0.1) & 20 & 0.22 & 0.14 & 0.23 & 0.11 \\
Kargi & Logistic(0.1,0.02) & 25 & 0.11 & 0.05 & 0.11 & 0.05 \\
Logologo & Logistic(0.1,0.04) & 27 & 0.15 & 0.07 & 0.15 & 0.06 \\
North Horr & Logistic(0.06,0.03) & 22 & 0.07 & 0.05 & 0.07 & 0.05 \\
\hline
\end{tabular}

\begin{tabular}{|l|cc|cc|}
\hline \multirow{2}{*}{$\begin{array}{c}\text { Variable } \\
\text { (Best-fit distn) }\end{array}$} & \multicolumn{2}{|c|}{ Estimated } & \multicolumn{2}{c|}{ Simulated } \\
\cline { 2 - 5 } & Mean & S.D. & Mean & S.D. \\
\hline Houehold's beginning herd size $\mathrm{H}_{\mathrm{ilt}}$ (TLU) \\
\hline Lognorm(30.2,9.6,RiskShift(-15.3) & 12 & 10 & 12 & 8 \\
InvGauss(37.5,60.8,RiskShift(-4.3) & 33 & 31 & 34 & 29 \\
InvGauss(19.8,33.7,RiskShift(-2)) & 18 & 15 & 17 & 14 \\
Normal(29.6,15.1) & 26 & 17 & 30 & 15 \\
\hline
\end{tabular}




\section{Appendix 4: Summary of Baseline Simulation Results}

Household-specific mortality rate (\%) $\mathrm{M}_{\mathrm{ilt}}$

\begin{tabular}{|l|cccc|cccc|}
\hline \multirow{2}{*}{ Location } & \multicolumn{3}{|c|}{ Observed in PARIMA (2000-2002) } & \multicolumn{4}{c|}{ Simulated (1982-2008) } \\
\cline { 2 - 9 } & Mean & S.D. & Min & Max & Mean & S.D. & Min & Max \\
\hline Dirib & 0.21 & 0.29 & 0.00 & 1.00 & 0.19 & 0.20 & 0.00 & 1.00 \\
Kargi & 0.11 & 0.12 & 0.00 & 0.50 & 0.11 & 0.10 & 0.00 & 0.95 \\
Logologo & 0.15 & 0.19 & 0.00 & 0.74 & 0.14 & 0.15 & 0.00 & 1.00 \\
North Horr & 0.07 & 0.10 & 0.00 & 0.37 & 0.07 & 0.08 & 0.00 & 0.54 \\
\hline
\end{tabular}

Household-specific non-mortality growth rate in $(\%) \mathrm{g}_{\mathrm{ilt}}$

\begin{tabular}{|l|cccc|cccc|}
\hline \multirow{2}{*}{ Location } & \multicolumn{3}{|c|}{ Estimated (2000-2002, 2007-2008) } & \multicolumn{4}{c|}{ Simulated (1982-2008) } \\
\cline { 2 - 9 } & Mean & S.D. & Min & Max & Mean & S.D. & Min & Max \\
\hline Dirib & -0.05 & 0.12 & -0.22 & 0.14 & -0.07 & 0.14 & -0.84 & 0.38 \\
Kargi & 0.05 & 0.07 & -0.22 & 0.22 & 0.04 & 0.12 & -0.23 & 0.38 \\
Logologo & 0.02 & 0.10 & -0.22 & 0.30 & 0.01 & 0.14 & -0.23 & 0.38 \\
North Horr & 0.07 & 0.11 & -0.22 & 0.22 & 0.08 & 0.07 & -0.23 & 0.38 \\
\hline
\end{tabular}

Household-specific herd size $\mathrm{H}_{\mathrm{ils}}$

\begin{tabular}{|l|cccc|cccc|}
\hline \multirow{2}{*}{ Location } & \multicolumn{3}{|c|}{ Observed (2000-2002, 2007-2008) } & \multicolumn{4}{c|}{ Simulated } \\
\cline { 2 - 8 } & Mean & S.D. & Min & Max & Mean & S.D. & Mean & S.D. \\
\cline { 2 - 8 } & 5 & 8 & 0 & 30 & 6 & 10 & 6 & 16 \\
Dirib & 21 & 39 & 0 & 224 & 20 & 43 & 43 & 38 \\
Kargi & 15 & 17 & 1 & 64 & 16 & 21 & 14 & 23 \\
Logologo & 24 & 32 & 0 & 53 & 24 & 33 & 68 & 37 \\
North Horr & 24 &
\end{tabular}




\section{Appendix 5: Summary of Risk Preference Elicitation}

Table below represents our risk game similar to Binswanger (1980). Though this simple elicitation method produces coarse categorical estimates of risk aversion, they work well compared to more complicated methods, especially among subjects with little or no literacy (Dave et al. 2010; Dohmen et al. 2007; Anderson and Mellor 2008). We estimate the range of coefficients of relative risk aversion implied by each possible choice of gambles under the assumption of constant relative risk aversion (CRRA) according to:

$$
E(U(P))=\sum_{k} \pi_{k} U\left(P_{k}\right)=\sum_{k} \pi_{k}\left(\frac{P_{k}^{1-R}}{1-R}\right) \quad, U^{\prime}(P)>0,0 \leq \pi \leq 1 \text { and } k=1,2
$$

$\pi$ represents probability of each possible payoff $\mathrm{P}$ and $R$ is the CRRA coefficient. In each case, the upper (lower) bound of $R$ can be calculated as the value of $R$ that generates same utility level for the payoffs associated with the preferred gamble and the less (more) risky adjacent. Following Binswanger (1980), we assign a mean CRRA measures to each of the ranges using the geometric mean of the two end points. We then assign each household to one of the six risk aversion classifications (extreme, severe, intermediate, moderate, low/neutral and neutral/risk seeker).

\section{Summary of Risk Preference Elicitation Set-Up}

\begin{tabular}{cccccccc}
\hline Lotteries & $\begin{array}{c}\text { Low } \\
\text { Payoff }\end{array}$ & $\begin{array}{c}\text { High } \\
\text { Payoff }\end{array}$ & $\begin{array}{c}\text { Expected } \\
\text { Payoff }\end{array}$ & $\begin{array}{c}\text { S.D. } \\
\text { Payoff }\end{array}$ & CRRA intervalGeometric mean & Risk class \\
\hline A & 100 & 100 & 100.0 & 0.0 & $\mathrm{R}>7.5$ & $7.5^{*}$ & extreme \\
B & 90 & 190 & 140.0 & 141.4 & $1.74<\mathrm{R}<7.5$ & 3.61 & severe \\
C & 80 & 240 & 160.0 & 226.3 & $0.81<\mathrm{R}<1.74$ & 1.19 & intermediate \\
D & 60 & 300 & 180.0 & 339.4 & $0.31<\mathrm{R}<0.81$ & 0.50 & moderate \\
E & 20 & 380 & 200.0 & 509.1 & $0<\mathrm{R}<0.31$ & $0.15^{* *}$ & slightly-to-neutral \\
F & 0 & 400 & 200.0 & 565.7 & $\mathrm{R}<0$ & $0^{* * *}$ & neutral-to negative \\
\hline
\end{tabular}

*Assume the lower bound, ** Arithmatic mean was used, *** Assume the upper bound, i.e., risk neutral 
Below are plots the cumulative distributions of CRRA associated with each of the three livestock wealth strata used in the 2008 survey.

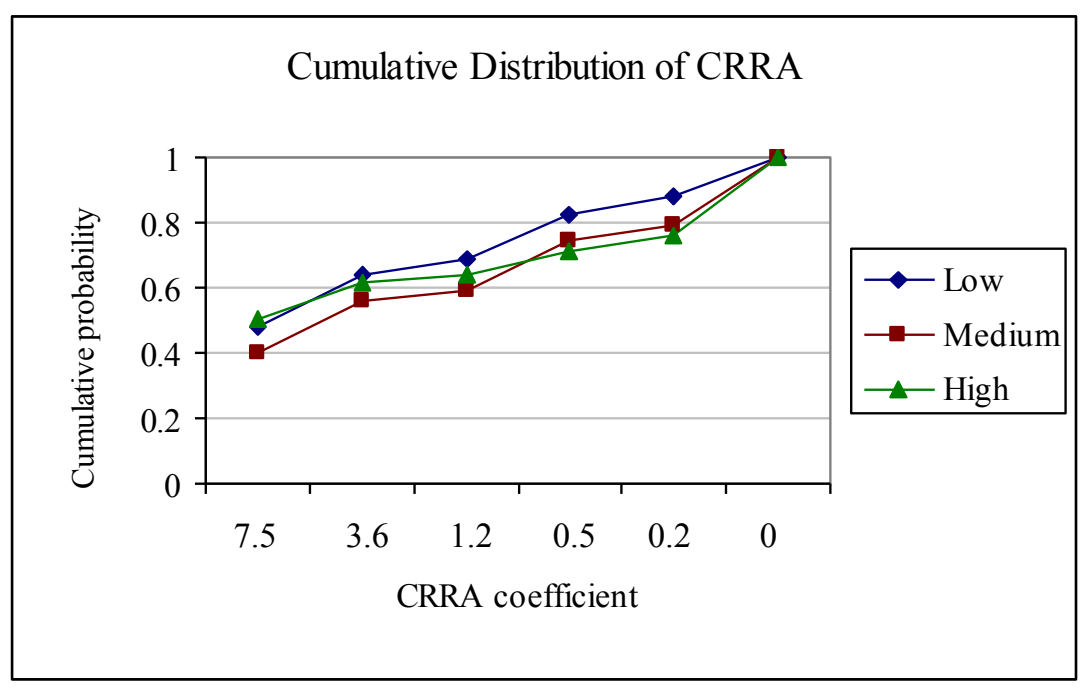

